\title{
Review: Cyclodextrin Inclusion Complexes Probed by NMR Techniques
}

\author{
Francisco B. T. Pessine, Adriana Calderini and Guilherme L. Alexandrino \\ Department of Physical Chemistry, Chemistry Institute, State University of Campinas
}

Brazil

\section{Introduction}

Cyclodextrins (CDs) are cyclic oligomers of glucopyranose units that play an important role as a host in inclusion complexes, where non-covalent interactions are involved. They have been extensively studied in supramolecular chemistry. Because of its biocompatibility, relatively non-toxicity and relatively low price, CDs have been widely employed for encapsulation of several substances, being used in food, cosmetic and pharmaceutical industries. Nuclear Magnetic Resonance spectroscopy (NMR) is one of the most useful techniques to study interactions of cyclodextrins with guest compounds. It is relatively easy to apply, the experiments are fast and it is the only technique that provides information on the right orientation of the guest molecule inside the cavity and also on other important parameters related to the physico-chemical characteristics of the inclusion complexes. In this review, it will be discussed the study of inclusion complexes between drugs and cyclodextrins by different NMR techniques. Initially, a brief introduction of the properties of cyclodextrins, its importance as innovative drug carrier systems and its applicability is reviewed. Then different NMR techniques used for characterization of inclusion complexes are detailed, with examples studied in our group, which involves since simple measures of ${ }^{1} \mathrm{H}-\mathrm{NMR}$ spectrum to more sophisticated experiments, e.g. Diffusion Ordered SpectroscopY (DOSY), NOE methods (ROESY), T1 measure and solid NMR by ${ }^{13} \mathrm{C}$ Cross-Polarization Magic Angle Spinning (CPMAS).

\section{Properties of cyclodextrins}

Cyclodextrins (CDs) as complexation agents and its study in supramolecular chemistry have been used in many areas (Steed \& Atwood, 2002; Chen \& Jiang, 2011). Cyclodextrins are cyclic oligosaccharides classified according to their number of glucopyranose units. The natural and most employed cyclodextrins are crystalline, homogeneous, non-hygroscopic substances and includes $\alpha$-cyclodextrin ( $\alpha \mathrm{CD}$, cyclohexaamylose, 6 units of glucopyranose), $\beta$-cyclodextrin ( $\beta C D$, cycloheptaamilose, 7 units of glucopyranose) and $\gamma$-cyclodextrin $(\gamma C D$, cyclooctaamylose, 8 units of glucopyranose), whose chemical structures are shown in Figure 1 (Szejtli, 1998). They are biocompatible, non-toxic in a wide range of concentration, relatively inexpensive and produced naturally by enzyme degradation of starch (Yorozu et al., 1982). 


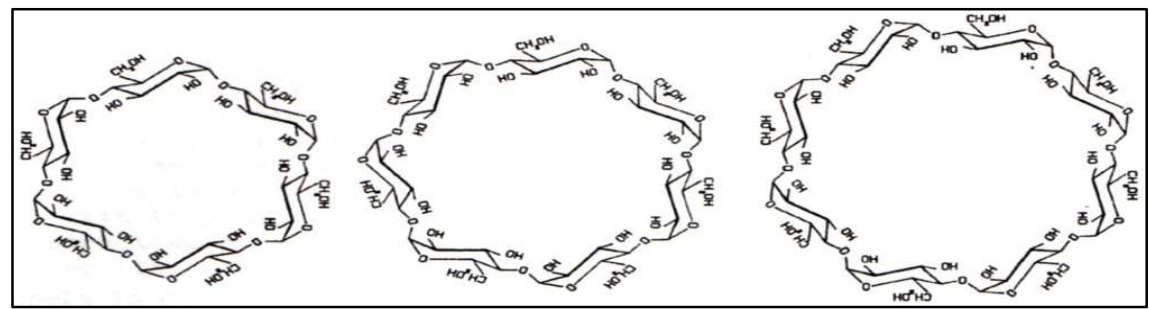

Fig. 1. Chemical structures of (a) $\alpha \mathrm{CD}$; (b) $\beta C D$; (c) $\gamma \mathrm{CD}$

These cyclodextrins have torus-like macro ring shape, are relatively low soluble in water and have a hydrophobic cavity. The main factors acting as driving force to form complexes and also responsible for the stability of these complexes are hydrophobic forces, the sizes of molecules/cavity and the guest properties (Griffiths \& Bender, 1973).

The glucopyranosides units are in $\mathrm{C} 1$ conformation, where the $\mathrm{OH}$ groups are linked to the carbon atoms $\mathrm{C} 2$ and $\mathrm{C} 3$ around the bigger edge and the more reactive $\mathrm{OH}$ group (linked to C6) is in the smaller edge. The cavity is delined by the hydrogens atoms and by the glucosidal bridge. The non-ligant electron pairs of the oxygen atoms are inner of cavity, leading to a high electron density and resulting in an environment similar to that of Lewis bases (Szejtli, 1988).

Casu et al. (Casu et al., 1966, 1968), had applying Nuclear Magnetic Resonance and Rotatory Optical Dispersion techniques, to DMSO solution containing CDs, where there is a strong competition with the solvent molecules by the intramolecular hydrogen bridge, showing that the glucose residues kept their conformation and the hydrogen bridge bonds in both solid state and in solution, where this competition is much lower, although, in solution, there is much more conformational mobility than in the solid state.

Bergeron (1977) and Saenger (1980) studied the formation of hydrogen bridges between the $\mathrm{OH}$ groups of the $\mathrm{C} 2$ and $\mathrm{C} 3$ atoms and observed that the conformational mobility of the macro cyclic ring is restricted, contributing to its toughness, both in solid and solution. This array keeps the linkages directed to the core of the cavity, leading to a hydrophobic environment, although the outer surface is hydrophilic, as shown in Figure 2. Some CDs structural and physical-chemical parameters are in Table 1.

\begin{tabular}{|c|c|c|c|}
\hline Properties & $\alpha$ CD & $\beta$ CD & $\gamma$ CD \\
\hline Number of glucopyranose units & 6 & 7 & 8 \\
\hline Molar mass / $(\mathrm{g} / \mathrm{mol})$ & 972 & 1135 & 1297 \\
\hline Solubility / $(\mathrm{g} / 100 \mathrm{~mL})$ & 14.5 & 1.85 & 23.2 \\
\hline Inner cavity diameter / $(\AA)$ & $4.7-5.2$ & $6.0-6.4$ & $7.5-8.3$ \\
\hline Outer cavity diameter / $(\AA)$ & 14.6 & 15.4 & 17.5 \\
\hline Cavity height / $(\AA)$ & 6.7 & 7.0 & 7.0 \\
\hline Specific rotation $(\alpha) \mathrm{D}^{25^{*}}$ & $150.5 \pm 0.5$ & $162.5 \pm 0.5$ & $177.4 \pm 0.5$ \\
\hline Volume of the cavity / $\left(\AA^{3}\right)$ & 174 & 262 & 427 \\
\hline$\Delta \mathrm{H}^{0}(\mathrm{aq}) /(\mathrm{kcal} / \mathrm{mol})$ & 7.67 & 8.31 & 7.73 \\
\hline$\Delta \mathrm{S}^{0}(\mathrm{aq}) /(\mathrm{cal} /(\mathrm{mol} \mathrm{K}))$ & 13.8 & 11.7 & 14.7 \\
\hline
\end{tabular}

Table 1. $\alpha, \beta$ and $\gamma \mathrm{CD}$ water solubility $\left(25^{\circ} \mathrm{C}\right)$ and structural parameters (Szejtli, 1988, 1998; Connors, 1997) 


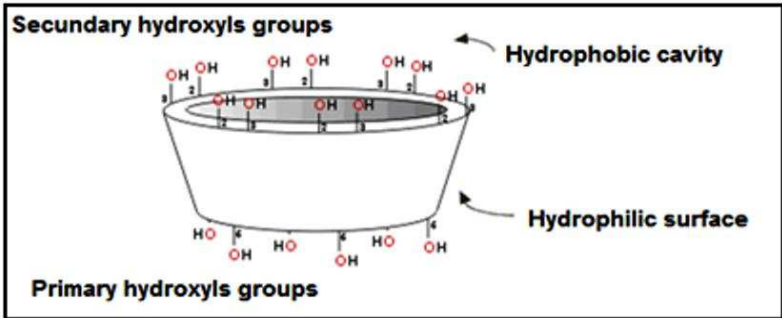

Fig. 2. CDs structure in torus-like macro ring shape, with the hydroxyls groups (Uekama et al., 1998)

The cavity size increases with the number of glucose units, although the height is constant (6.7-7.0 $\AA$ ). The solubility do not follow this rule: $\beta C D$ is considerably less soluble in water than $\alpha \mathrm{CD}$ and $\gamma \mathrm{CD}$ and this low solubility is due to the hydrogen bridges between $\mathrm{OH}$ groups of $\mathrm{C} 2$ and $\mathrm{C} 3$, leading to a rigid structure. In the $\alpha \mathrm{CD}$ molecule, one glucose unit in distorted and only 4 of 6 possible hydrogen bridges are formed. In $\gamma \mathrm{CD}$, its glucose units are not in the same plane and its structure is more flexible; therefore, this CD have higher solubility in aqueous solutions (Uekama et al., 1998).

Although the solubility of $\beta C D$ is smaller, the size of its cavity is more appropriate to encapsulate a great variety of molecules with biological and pharmacological properties. Chemical substitution of the $\mathrm{OH}$ groups in $\mathrm{C} 2, \mathrm{C} 3$ and $\mathrm{C} 3$ have been done to increase its solubility, as for example, the hydroxipropyl- $\beta C D$.

Some factors should be considered to choose the type of the CD for a given study: physicalchemical properties of the guest, size of the CD cavity, solubility, the preparation method and possibility of co-encapsulation. Basically, the inclusion complexes involves interactions of the molecules of both the host and the guest, and it is a combination of different noncovalent interactions as ionic, dipolar, electronic, van der Waals and the hydrophobic effect, besides the size and the shape of the molecules (Chen \& Jiang, 2011).

The stability of the inclusion complex is due to, primarily, hydrophobic forces. The association constant is, usually, in the order of $10^{-3} \mathrm{M}$, typical of weak interactions (Griffiths \& Bender, 1973). Hydrophobic molecules, or only the hydrophobic part of a polar molecule, are incorporated in the $\mathrm{CD}$ cavity promoting the shift of the water molecules from inside the cavity, which is favored by repulsions between the apolar guest and the water polar molecule. This process leads to the partial or total encapsulation of the guest molecule, increasing aqueous solubility of the sample. However, when the inclusion complex is diluted in a larger volume, the phenomenon is reverted and the species is free in solution.

The main advantages of using CDs in drug delivery systems includes: the increase the biodisponibility, solubility enhancer, improve the stability of the drug, increase the therapeutic index, the efficacy/pharmacokinetics properties, and decrease the drug toxicity (Uekama et al., 1998).

The applicability of CDs includes: analytical chemistry as chromatographic separations (Li \& Purdy, 2002), drug delivery systems (Arun et al., 2008), as masking agent in food 
(Tamamoto et al., 2010), cosmetics (Schmann \& Schollmeyer, 2002), in hydrogels (Hoarea \&. Kohaneb, 2008) and in contact lenses (Santos et al., 2009).

\section{Nuclear Magnetic Resonance spectroscopy}

\section{$3.1{ }^{1} \mathrm{H}-$ Nuclear Magnetic Resonance spectroscopy}

Nuclear Magnetic Resonance spectroscopy has been extensively employed in Chemistry and can be considered as one of the most complete spectroscopic techniques, due to its wide field of applications from structural elucidation of structures to investigations on intra/inter-molecular. Applications of NMR on CDs chemistry is so important that no other spectroscopic technique can provide the same wealth of chemical information on the supramolecular systems. Other spectroscopic techniques, like molecular UV-Vis absorption, fluorescence emission, circular dichroism, etc., are also suitable for thermodynamic study of the host-guest intermolecular interactions, but they give only indirect information on the molecular structure of the inclusion complexes.

The simplest experiment of NMR as an indicative of complexation is the observation of the difference in the proton chemical shifts between the free guest and host species and the suggested complex. There has been a long time since Demarco \& Thakkar (Demarco \& Thakkar, 1971) started studies on CDs complexes by observing the chemical shifts changes of the protons $\mathrm{H} 3$ and $\mathrm{H} 5$ inside the cavity of $\alpha \mathrm{CD}$ when in presence of aromatic molecules due to the anisotropic effect of the aromatic ring. When there is a host-guest interaction, it leads to a change in the $\delta$ of the hydrogens due the complexation. This is a first evidence of the guest inclusion in the CD cavity (Schneider et al., 1998). The CDs protons are named according Figure 3.

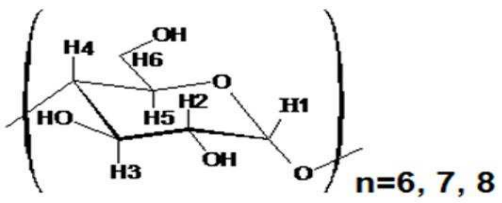

Fig. 3. NMR protons for $\alpha ; \beta ; \gamma \mathrm{CD}(\mathrm{n}=6 ; 7 ; 8$, respectively)

The ${ }^{1} \mathrm{H}-\mathrm{NMR}$ spectra of the three natural cyclodextrins are shown in Figure 4.

One can see that the differences among the spectra of the three CDs, due to the proton shielding, are smaller than $0.1 \mathrm{ppm}$. The characteristics of these spectra are discussed elsewhere (Schneider et al., 1998).

The stability of the inclusion complex and the orientation of the drug molecule can be inferred by this experiment. Greatbanks \& Pickford (Greatbanks \& Pickford, 1987) concluded that when $\Delta \delta \mathrm{H} 3>\Delta \delta \mathrm{H} 5$, occurs partial inclusion of the guest inside the cavity and when $\Delta \delta \mathrm{H} 3 \leq \Delta \delta \mathrm{H} 5$, a total inclusion takes place.

As an example, the stability of the inclusion complex between Minoxidil (MNX), a vasodilator drug also used for treatment of alopecia areata (Gorecki, 1988), and the natural CDs can be suggested by analyzing the differences between the protons chemical shifts of both species. Figure 5 shows the MNX structure and the protons assignment. 


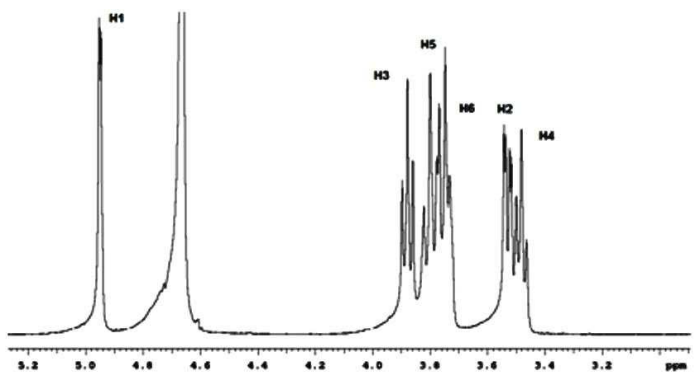

(a)

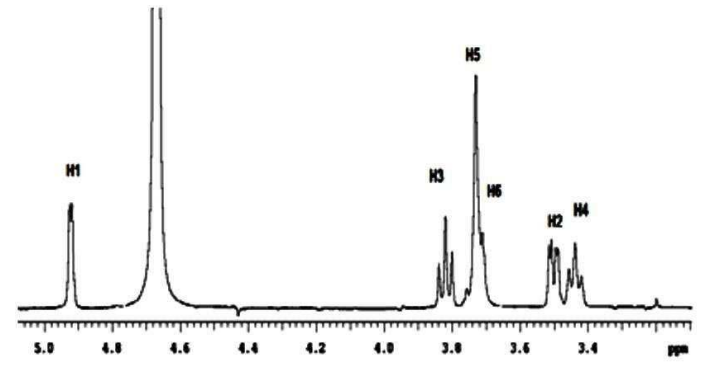

(b)

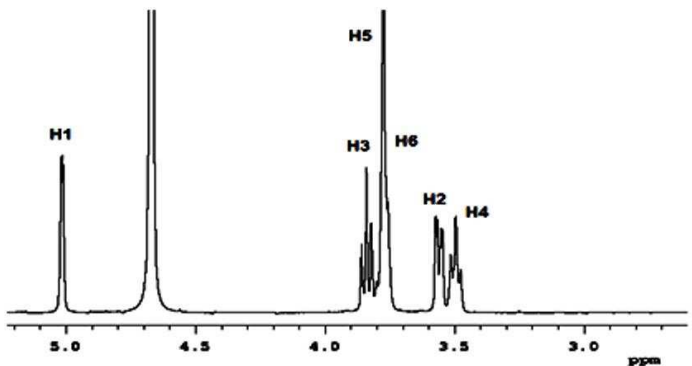

(c)

Fig. 4. ${ }^{1} \mathrm{H}-\mathrm{NMR}$ spectra of the natural cyclodextrins $\left(298 \mathrm{~K} ; 500 \mathrm{MHz} ; \mathrm{D}_{2} \mathrm{O} ; \delta_{\mathrm{HOD}} 4.67 \mathrm{ppm}\right)$ : (a) $\alpha \mathrm{CD}$; (b) $\beta \mathrm{CD}$; (c) $\gamma \mathrm{CD}$

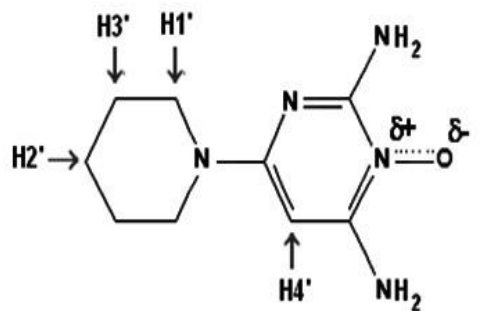

Fig. 5. Structure of MNX and its protons 
Tables 2 and 3 summarized the data for this complex.

\begin{tabular}{|c|c|c|c|c|c|c|c|c|c|}
\hline \multirow{2}{*}{$\mathbf{H}$} & \multirow{2}{*}{$\frac{\alpha \mathrm{CD}}{\delta_{\alpha \mathrm{CD}}}$} & \multicolumn{2}{|c|}{ MNX: $\alpha$ CD } & \multirow{2}{*}{$\frac{\beta C D}{\delta_{\beta C D}}$} & \multicolumn{2}{|c|}{ MNX: $\beta C D$} & \multirow{2}{*}{$\begin{array}{l}\gamma \mathrm{CD} \\
\delta_{\gamma \mathrm{CD}}\end{array}$} & \multicolumn{2}{|c|}{ MNX: $\gamma$ CD } \\
\hline & & $\delta_{\alpha \mathrm{CD}: \mathrm{MNX}}$ & $\Delta \delta_{\alpha \mathrm{CD}: \mathrm{MNX}}$ & & $\delta_{\beta \mathrm{CD}: \mathrm{MNX}}$ & $\Delta \delta_{\beta} \mathrm{CD}: \mathrm{MNX}$ & & $\delta_{\gamma} \mathrm{CD}: \mathrm{MNX}$ & $\Delta \delta_{\gamma} \mathrm{CD}: \mathrm{MNX}$ \\
\hline 1 & 4.960 & 4.955 & -0.005 & 4.960 & 4.965 & 0.005 & 5.015 & 5.015 & -- \\
\hline 2 & 3.530 & 3.540 & 0.010 & 3.545 & 3.550 & 0.005 & 3.560 & 3.555 & -0.005 \\
\hline 3 & 3.910 & 3.890 & -0.020 & 3.830 & 3.820 & -0.010 & 3.860 & 3.850 & -0.010 \\
\hline 4 & 3.490 & 3.480 & -0.010 & 3.490 & 3.480 & -0.010 & 3.495 & 3.490 & -0.005 \\
\hline 5 & 3.765 & 3.750 & -0.015 & 3.720 & 3.710 & -0.010 & 3.800 & 3.800 & -- \\
\hline
\end{tabular}

Table 2. CDs chemical shifts $(\delta)$ and their difference when in presence of MNX $\left(\Delta \delta=\delta_{\text {complexed }}-\delta_{\text {free }}\right)$

\begin{tabular}{|c|c|c|c|c|c|c|c|}
\hline \multirow{2}{*}{$\mathbf{H}$} & \multirow{2}{*}{$\frac{\text { MNX }}{\delta_{\mathrm{MNX}}}$} & \multicolumn{2}{|c|}{ MNX: $\alpha$ CD } & \multicolumn{2}{|c|}{ MNX:ßCD } & \multicolumn{2}{|c|}{ MNX: $\gamma C D$} \\
\hline & & $\delta_{\alpha \mathrm{CD}: \mathrm{MNX}}$ & $\Delta \delta_{\alpha \mathrm{CD}: \mathrm{MNX}}$ & $\delta_{\beta \mathrm{CD}: \mathrm{MNX}}$ & $\Delta \delta_{\beta \mathrm{CD}: \mathrm{MNX}}$ & $\delta_{\gamma \mathrm{CD}: \mathrm{MNX}}$ & $\Delta \delta_{\gamma} \mathrm{CD}: \mathrm{MNX}$ \\
\hline $1^{\prime}$ & 3.340 & 3.360 & 0.020 & 3.420 & 0.080 & 3.340 & --- \\
\hline $2^{\prime}$ & 1.535 & 1.550 & 0.015 & 1.570 & 0.035 & 1.535 & --- \\
\hline $3^{\prime}$ & 1.455 & 1.490 & 0.035 & 1.520 & 0.065 & 1.455 & --- \\
\hline
\end{tabular}

Table 3. MNX chemical shifts $(\delta)$ and their difference when in presence of CDs $\left(\Delta \delta=\delta_{\text {complexed }}-\delta_{\text {free }}\right)$

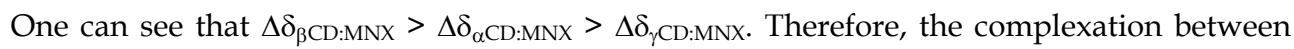
$\beta C D$ and MNX is stronger than in $\alpha$ and $\gamma \mathrm{CD}$. Considering the values of $\Delta \delta$ for $\mathrm{H} 3$ and $\mathrm{H} 5$, there is a partial inclusion in $\alpha$ and $\gamma \mathrm{CD}$. For the complex $\beta C D$ :MNX, the inclusion is total. These results were confirmed by other spectroscopic techniques.

Other drug that we had performed NMR studies with CDs is the anti-neoplasic 5fluorouracil. No differences in the chemical shifts were observed. This lack of interaction was supposed to be due to the relatively high polarity and solubility of the drug in aqueous media (12.2 mg/mL) (Bayomi \& Al-Badr, 1990).

Despite the chemical shift changes of ${ }^{1} \mathrm{H}$ from $\mathrm{CD}^{\prime} \mathrm{s}$ inner cavity the characterization of inclusion complexes with NMR could be done. This same experimental evidence also could be observed for ${ }^{1} \mathrm{H}$ from the guest molecule inserted into the $\mathrm{CD}$ cavity. Moreover, this chemical shift analysis could be extended for other types of experiments, and the characterization of different properties around the complex supramolecular organization can be obtained easily.

One of the most employed NMR experiment based on chemical shift changes is NMR titration. In this experiment, NMR spectra are obtained for solutions containing a fixed concentration of guest $\left[\mathrm{G}_{\mathrm{o}}\right]$, but the initial concentration of the $\mathrm{CD}\left[\mathrm{CD} \mathrm{O}_{\mathrm{O}}\right]$ is variable. Due to the chemical equilibrium of G:CD complex formation (equation 3.1), the increase on $C D$ concentration in the solution will result in more population of the G:CD inclusion complex, consequently, it is expected more chemical shift changes in interacting host and guest nucleus as may be the higher $\mathrm{CD}$ concentration in the solution. Besides the $\mathrm{CD}$ concentration, the magnitude of equilibrium constant associated to the complex formation (K) will be directly related to the chemical shift changes, because it represents the thermodynamic tendency through the formation of G:CD complex, equation 3.2. 


$$
\begin{gathered}
{[\mathrm{G}]+[\mathrm{CD}]=[\mathrm{G}: \mathrm{CD}]} \\
\mathrm{K}=\{[\mathrm{G}: \mathrm{CD}] /([\mathrm{G}][\mathrm{CD}]\}
\end{gathered}
$$

[G] and [CD] are the concentration of free guest and CD in the equilibrium, respectively, which is defined, for a 1:1 complex, according to their respective mass balance (equations 3.3 and 3.4).

$$
\begin{aligned}
{[G]+[G: C D] } & =G_{O} \\
{[C D]+[G: C D] } & =C_{O}
\end{aligned}
$$

As the chemical shift changes in the experiment is defined as the molar weighted average of free and complexed G or CD molecules (equation 3.5), the correlation among the equations 3.2-3.5 can provide a non-linear math relationship between $\mathrm{K}$ and $\delta$ obs, which leads to a thermodynamic application of NMR to cyclodextrin inclusion complexes (Fielding, 2000).

$$
\delta \exp =\mathrm{X}_{\mathrm{G}} \delta_{\mathrm{G}}+\mathrm{X}_{\mathrm{G}: \mathrm{CD}} \delta_{\mathrm{G}: \mathrm{CD}}
$$

Examples of the linear relation between $\mathrm{K}$ and $\delta_{\mathrm{obs}}$ are those reported by Mathur et al. (Mathur et al., 1963), Hannah \& Ashbaugh (Hannah \& Ashbaugh, 1964) and Foster \& Fyfe (Foster \& Fyfe, 1965a,b). Using the Benesi-Hildebrand and Scatchard linear models they investigated the thermodynamic properties of guest:CD inclusion complex using UV-Vis spectroscopy (equations 3.6 and 3.7).

$$
\begin{gathered}
1 / \Delta \delta=1 /\left(\mathrm{K} . \Delta \delta \max \cdot\left[\mathrm{CD}_{\mathrm{O}}\right]\right)+1 / \Delta \delta \max \\
\Delta \delta /\left[\mathrm{CD}_{\mathrm{O}}\right]=-\mathrm{K} . \Delta \delta+\mathrm{K} . \Delta \delta \max
\end{gathered}
$$

$\Delta \delta=(\delta G-\delta \exp )$, is the chemical shift change of guest proton as the concentration of the CD increase, and $\Delta \delta \max =(\delta G-\delta G: C D)$, is the maximum possible chemical shift changes supposing all guest molecules are complexed with the CD. Equation 3.6 is known as the double reciprocal plot, and its deduction require an approximation that $\left[\mathrm{CD}_{\mathrm{O}}\right]$ must be at least 10 times higher than [Go]. Besides, weak inclusion complexes implies significant uncertainly on $\Delta \delta$, therefore, $\mathrm{K}$ estimation become prejudiced. Equation 3.7 is known as $\mathrm{x}$ reciprocal plot, and is less often found in articles of NMR in CD complexes (Fielding, 2000).

Another application of $\Delta \delta$ is the determination of most stable molar stoichiometry of guest:CD in solution, which can be done through the Job plot experiment, that was initially developed for optical spectroscopy and adapted to NMR. $\Delta \delta$ is calculated in solution with different guest molar fraction $r$, and the stoichiometry relation is obtained for the $r$ value that show the higher $\Delta \delta$, which corresponds to the maximum population of inclusion complex in solution. If the complex most stable stoichometry is $1: 1, \Delta \delta$ will be maximum in the solution of $r 0.5$, while if guest:CD complex is 1:2, the higher $\Delta \delta$ will occur for $r 0.33$. The principle of this method is based on the mass balance of each specie guest, CD and guest:CD complex in equilibrium, that depend on the $r$ value according to equations 3.8 and 3.9 (Loukas, 1997).

$$
\begin{gathered}
{[G]=r M-[G: C D]} \\
{[C D]=M(1-r)-n[G: C D]}
\end{gathered}
$$


where $r$ is the guest molar fraction, $M=[G]+[C D]$ and $n$ is the number of $C D$ molecules that encapsulate the guest. The maximum [G:CD] can be determined as a function of $r$ calculating $d[G: C D] / d r=0$ that gives $r=(n+1)^{-1}$. Therefore, for $n=1$ (1:1 guest:CD complex) [G:CD] will be higher in the solution which $r$ must be 0.5 .

As the thermodynamic models for $\mathrm{K}$ prediction assumes a fixed stoichometry for the guest:CD complex, equations assuming different stoichometries can also be adjusted, which could lead to uncorrected predictions of guest:CD molar relation. Then, this experiment become very important for study of CDs inclusion complexes, as NMR allow any kind of guest to be investigated, because it does not depend on guest optical spectroscopy activity.

\section{2 $\mathrm{T}_{1}$ measurement}

The $\mathrm{T}_{1}$ measurement is directly related to the relaxation phenomenon, then it will be given a brief review about it. In NMR experiments, the irradiation of the resonance frequency disturbs the thermal equilibrium of the spin system, changing the population ratio and causing appearance of transverse field magnetic components $\left(\mathrm{M}_{\mathrm{x}}\right.$ and $\left.\mathrm{M}_{\mathrm{y}}\right)$. The relaxation occurs when the perturbation ceases until it reaches the equilibrium. It can be divided in two different processes:

1. The relaxation in the applied field direction is characterized by the spin-lattice or longitudinal relaxation time $\mathrm{T}_{1}$ and will be discussed further,

2. The relaxation perpendicular to the field direction, which is characterized by the spinspin or transverse relaxation time.

The time needed for the relaxation of nuclear system is very small which may be seconds, minutes or hours. For protons under high-resolution, $\mathrm{T}_{1}$ is in the order of a second (Friebolin, 1993; Günther, 1994).

As discussed in the previous paragraph, immediately after exposing the spins to $B_{0}$ (the external magnetic field), they are in a non-equilibrium state because all spin states are equally populated and $\mathrm{M}_{0}$ (initially $\mathrm{M}_{\mathrm{z}}$ ) $=0$, i.e., the magnetization vector $\mathrm{M}_{0}$ is rotated by $90^{\circ} x^{\prime}$ pulse into the axis direction $y^{\prime}$, or by a $180^{\circ} x^{\prime}$ pulse into the negative $z$ direction, leading to $M_{z}=0$. After a $180^{\circ}$ x pulse, its new value is $M_{0}=-M_{z}$ as in Figure 6 (Friebolin, 1993).

The population ratio changes because the $90^{\circ} x^{\prime}$ pulse equalizes the population of the two energy levels, whereas the $180^{\circ} x^{\prime}$ pulse inverts the population ratio. Therefore, after the perturbation, the equilibrium condition is reached when $\mathrm{M}_{\mathrm{z}}=\mathrm{M}_{0}$ and the rate at which it occurs is determined by the spin-lattice relaxation time $T_{1}$. This process was described by the Bloch's differential equation (Friebolin, 1993).

$$
\frac{d M_{z}}{d t}=-\frac{M_{z}-M_{0}}{T_{1}}
$$

where $\mathrm{T}_{1}^{-1}$ is the rate constant of the relaxation, which is a first-order process.

$\mathrm{T}_{1}$ can be understood by a change in the energy in the spin system, as the energy absorbed form the pulse must be given up again, transferring to the lattice (or the surroundings), 
whose thermal energy increases. Intra and intermolecular interactions like dipole-dipole, spin rotation, anisotropy, etc., can contribute to the spin-lattice relaxation. This is recognized as a significant phenomenon related to the dynamic properties of molecules. The most used method to determine $T_{1}$ is the inversion recovery method (Günther, 1994), as seen in Figure 7.

A)

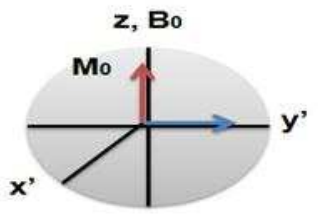

A. 1

B)

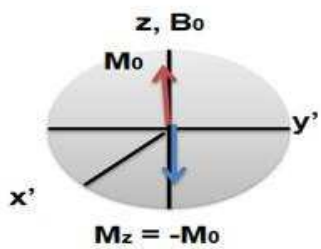

B.1

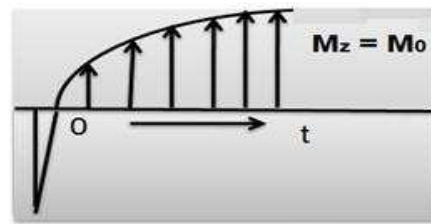

A. 2

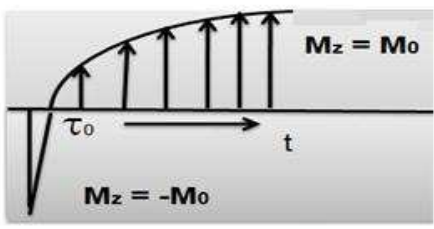

B.2

Fig. 6. The longitudinal component $\mathrm{M}_{\mathrm{z}}$ in the rotating coordinate system $\mathrm{x}^{\prime} ; \mathrm{y}^{\prime} ; \mathrm{z}$ : A) after a $90^{\circ} x^{\prime}$ pulse; B) after a $180^{\circ} x^{\prime}$ pulse

Consider the macroscopic magnetization $\mathrm{M}_{0}$ in the rotating coordinate system.

1. A $180^{\circ}$ pulse at the beginning of the experiment brings the vector $\mathrm{M}_{0}$ to the negative $\mathrm{z}$ direction,

2. The value of $\mathrm{M}_{0}$ decreases due to the spin-lattice relaxation at time $\tau_{1}$,

3. $\mathrm{M}_{0}$ passes through zero at time $\tau_{0}$,

4. $\mathrm{M}_{0}$ begins to increase in the positive $\mathrm{z}$-direction at time $\tau_{2}$ reaching its final value.
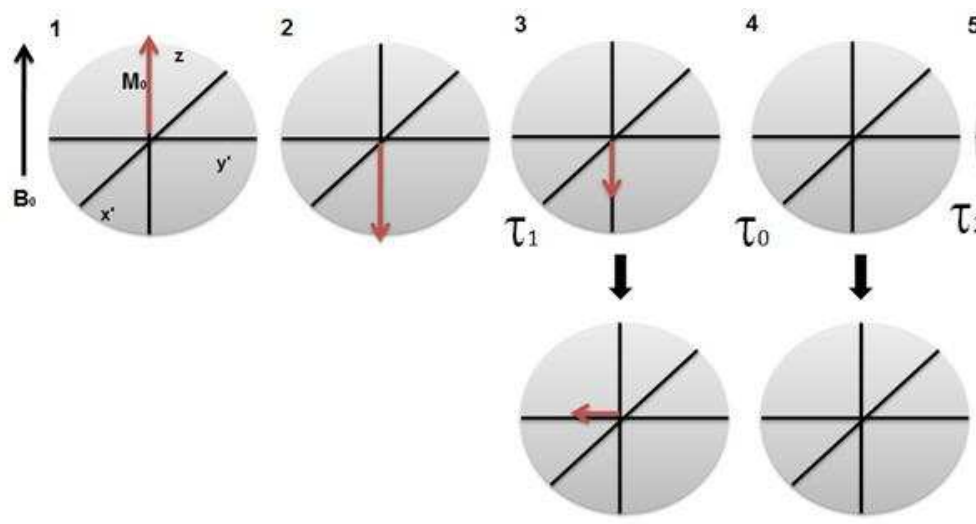

5
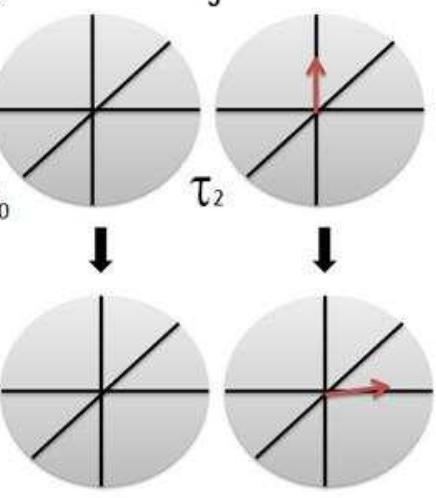

Fig. 7. The inversion-recovery experiment for $\mathrm{T}_{1}$ measurement 
The magnetization can be detected by two signals, applying $90^{\circ}$ pulses at time $\tau_{1}$ and $\tau_{2}$ which align $\mathrm{M}_{0}$ along the negative or positive $\mathrm{y}$-direction, respectively, differing in phase by $180^{\circ}$. At time $\tau_{0}$, there is no magnetization and no signal can be detected. Equation 3.11 is used to determine $\mathrm{T}_{1}$ (Günther, 1994).

$$
\tau_{0}=\mathrm{T}_{1} \ln 2=0.693 \mathrm{~T}_{1}
$$

In an alternative way, $\mathrm{T}_{1}$ can be determined more accurately from a semi logarithmic plot of the intensity changes $\mathrm{M}_{0}$ and $\mathrm{M}_{\mathrm{z}}$ against $\tau$, since it can be derived from equation 3.10 by integration (equation 3.12).

$$
\ln \left(M_{0}-M_{Z}\right)=\ln 2 M_{0}-\frac{\tau}{T_{1}}
$$

Therefore, longitudinal relaxation times (T1) give information about the nucleus mobility in solution and the interaction between host and guest molecules by a qualitative analysis of the decreasing of $\mathrm{T}_{1}$ values in the complexes (Lambert \& Mazzola, 2004). Grillo et al. (Grillo et al., 2007) showed that $T_{1}$ lowering of the hydroxymethylnitrofurazone and dimethyl$\beta c y c l o d e x t r i n$ system is a strong evidence of interactions between both molecules.

One of the inclusion compounds studied by this technique in our group was Dapsone: $\beta C D$, where the $T_{1}$ values for all hydrogens were obtained for each molecule and for the complex (data to be published). The values for each sample are summarized in Tables 4 and 5. The structure of Dapsone (DPS) is in Figure 8.

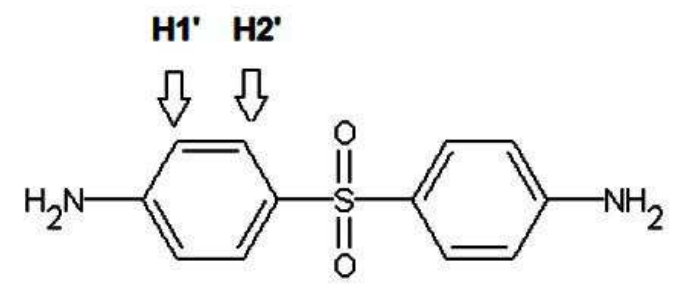

Fig. 8. Structure of Dapsone and the protons probed in NMR experiments

\begin{tabular}{|c|c|c|}
\hline Proton & T1 $1_{\text {DPS }}(\mathrm{s})$ & T1 \\
\hline DPS: $\beta C D$ & $(\mathrm{~s})$ \\
\hline${ }^{\prime}$ & $3.95 \pm 0.54$ & $1.02 \pm 0.16$ \\
\hline $2^{\prime}$ & $6.76 \pm 3.07$ & $1.73 \pm 0.22$ \\
\hline
\end{tabular}

Table 4. Longitudinal relaxation times (T1, s) of DPS hydrogens in presence of $\beta C D$

\begin{tabular}{|c|c|c|}
\hline Proton & $\mathrm{T}_{\beta \mathrm{CD}}(\mathrm{s})$ & $\mathrm{T}_{\mathrm{DPS}: \beta \mathrm{\beta D}}(\mathrm{s})$ \\
\hline H1 & $1.2 \pm 0.1$ & $0.73 \pm 0.07$ \\
\hline H3 & $1.56 \pm 0.13$ & $1.48 \pm 0.07$ \\
\hline H5 & $0.63 \pm 0.03$ & $0.39 \pm 0.03$ \\
\hline H4 & $0.91 \pm 0.06$ & $0.81 \pm 0.04$ \\
\hline
\end{tabular}

Table 5. Longitudinal relaxation times $(\mathrm{T} 1, \mathrm{~s})$ of $\beta \mathrm{CD}$ hydrogens in presence of DPS 
One observed that all $\mathrm{T}_{1}$ values decrease for the inclusion compound. Note that the $\mathrm{T}_{1}$ values obtained for the DPS hydrogens became at the same order as the $T_{1}$ values of $\beta C D$, indicating a strong host:guest interaction.

\subsection{DOSY experiment (Diffusion Ordered SpectroscopY)}

The molecular diffusion in solution is a phenomenon related to the molecular dynamics in biological and chemical systems, which can be probed by NMR. The diffusion coefficients D provide important information about the molecular organization and the phase structures. Typical D values in liquids (298-303 K) are from 10-12 $\mathrm{m}^{2} \mathrm{~s}^{-1}$ (polymers with high molecular weight) to $10^{-9} \mathrm{~m}^{2} \mathrm{~s}^{-1}$ (small molecules) (Stilbs, 1987).

Even though the molecular diffusion is not straightway related with interactions and spins energies, the relation of this property with the longitudinal $\left(\mathrm{T}_{1}\right)$ and transversal $\left(\mathrm{T}_{2}\right)$ times are better understood. Brownian motion perturbs the nuclei magnetic field, changes $\mathrm{T}_{1}$ and $\mathrm{T}_{2}$ (Price, 1997).

These studies started with the discovery of the spin echoes by Hahn in 1950. In this experiment, a pulse sequence $\left[90^{\circ}-\mathrm{t}-180^{\circ}-\mathrm{t}-(\mathrm{echo})-\right]_{\mathrm{n}}$ is applied and it will result in a perfect refocus of the nuclei magnetization (spin echoes) only if there is any changes in the magnetic field gradient $G$ applied during the time $2 \tau$. However, the molecular diffusion does not allow $G$ to keep totally homogeneous, decreasing the echoes amplitude in $2 \tau$. The relation between the spin echoes and the diffusion coefficient D is given by equation 3.13 (Souza \& Laverde, 2002).

$$
\frac{A(2 \tau)}{A(0)}=\exp \left[-\left(\frac{2 \tau}{\mathrm{T} 2}\right)-\frac{2}{3} \gamma^{2} G^{2} D \tau^{3}\right]
$$

The disadvantage in the Hahn equation is the difficulty in separate the contributions due to the transversal relaxation $\left(\mathrm{T}_{2}\right)$ and the molecular diffusion (D). This was solved by Carr and Purcell in 1954 , where the pulse sequence $90^{\circ}-\tau-\left[180^{\circ}-\tau-(\right.$ eco $)-\tau-180^{\circ}-\tau-(\text { eco)- }]_{n}$ can separate the $\mathrm{D}$ effect from the $\mathrm{T}_{2}$ effect (equation 3.14).

$$
\frac{A(t)}{A(0)}=\exp \left[-\left(\frac{t}{\mathrm{~T} 2}\right)\right] \exp \left[-\frac{1}{3}(\gamma G \tau)^{2} \mathrm{D} \tau\right]
$$

Even though the application of this sequence and the improvement on the echo amplitude with the Stimulated Spin Echo (STE), also discussed by Hahn in 1950, the application of static magnetic field gradients $(G)$ resulted in the necessity to use high values of $G$ to measure small values of $\mathrm{D}$, which led to a increase in the echo and, consequently, a decrease in the noise/signal ratio, causing a difficulty in the detection (Souza \& Laverde, 2002).

These difficulties were overcome with application of Pulsed Magnetic Field Gradients (PFG), with spin echoes (PFGSE) (Johnson, 1999) and stimulated spin echoes (PFGSTE) (Stilbs, 1987; Woessner, 1961; Tanner, 1970). Other advantages due to PFG are (Parella, 1998):

1. Reduction of the steps in the cycles phases to suppression of undesired artifacts,

2. Decrease of the signal acquisition time,

3. Noise reduction of the $2 \mathrm{D}$ experiment, 
4. Improvement of the spectral processing,

5. Efficient suppression of undesired signals, like solvent and heteronuclear coupling.

The advantages of PFG application are (Souza \& Laverde, 2002):

a. Separation of the echo attenuation caused by the $\mathrm{D}$ effect due to $T_{2}$, doing the experiment to a fix $\tau$ interval between the RF pulses and changing the area of the gradient pulse,

b. The spin echo is detected in a homogeneous magnetic field condition.

In 1992, Morris and Johnson (Morris \& Johnson, 1992) developed an analytical technique based on PFGSE that made possible the distinction among the components of a mixture by the molecular diffusion of each chemical shift. This technique was named DOSY (Diffused Ordered Spectroscopy). In this experiment, D is obtained from the decay of the signal intensity I, which is a function of the area of the magnetic field gradient $\mathrm{q}(\mathrm{q}=\mathrm{yg \delta})$. It can be correlated with $\mathrm{q}$ and $\mathrm{D}$ by equation 3.15 .

$$
\mathrm{I}(\mathrm{q}, \mathrm{v})=\sum\left[A n(v) \cdot \exp \left[-D n\left(\Delta-\frac{\delta}{3}\right) q^{2}\right]\right]
$$

where $A n(v)$ is the NMR signal intensity when $q=0$; Dn is the diffusion coefficient of the component $\mathrm{n}$ and $\Delta$ is the monitoring time. The DOSY spectrum has two dimensions: the chemical shift in the $\mathrm{x}$ axis and Dn in the $\mathrm{y}$ axis. It is obtained applying a Laplace inverse transformation after the signal processing by Fourier transformation.

The DOSY experiment allows a global analysis of the sample dynamics, involving since small molecules to aggregates and supramolecular structures. Besides, this technique presents other advantages as impurity detection with no interference, evaluation of the species in equilibrium and selection of the desired specie to analysis.

The small sensibilities of NMR technique, superposition of the signals and similar D values interfere with the acquisition of a good DOSY spectrum. Also, this experiment requires a good stability of the signal, which can be impaired by phenomena as induced vortex currents in the sample, coupling between the gradient coil and the principal magnetic field and perturbation in the system of lock frequency and field. So, to try to minimize such effects, various pulse sequences were developed, each with advantages and disadvantages according to the characteristics of the sample components. The main examples of DOSY pulse sequences are: BPPSTE (Bipolar Pulser Pair STimulated Echo), BPPLED (Bipolar Pulse Pair Longitudinal Eddy currents Decay), GCSTE (Gradient Compensated STimulated Echo) e GCSTESL (Gradient Compensated Stimulated Echo Spin Lock) (Souza \& Laverde, 2002).

The implementation of simple PFGSE experiments on cyclodextrins complexes was initiated with Stilbs in 1983 (Stilbs, 1987), and the group of Lin first studied this interaction by DOSY in 1995 (Lin et al., 1995). The formation of inclusion complex in a solution containing a drug and $\mathrm{CD}$ can be observed by reduction of its diffusion coefficient. The larger the difference between $\mathrm{D}$ in solution with $\mathrm{CD}$ compared to $\mathrm{D}$ obtained from solution without $\mathrm{CD}$, the higher the fraction of drug inclusion complex.

The diffusion coefficient (D) depends on the size of the molecule and it can be calculated by equation 3.16 . 


$$
D=\frac{\kappa T}{6 \pi \eta r}
$$

where $\kappa$ is the Boltzmann constant, $T$ is the absolute temperature, $\eta$ is the dynamic viscosity, and $r$ is the radius of the molecule. The population of the guest involved in this complexation process can be calculated from the diffusion coefficients observed for the species in the free and complexed forms, using the equations 3.17-3.19 (Lin et al., 1985; Rymdén et al., 1983).

$$
\mathrm{D}_{\text {observed }}=\mathrm{D}_{\text {free }} \mathrm{p}_{\text {free }}+\mathrm{D}_{\text {complexed }} \mathrm{p}_{\text {complexed }}
$$

where:

$$
\mathrm{p}_{\text {free }}+\mathrm{p}_{\text {complexed }}=1
$$

and:

$$
\mathrm{p}_{\text {free }}=1-\mathrm{p}_{\text {complexed }}
$$

$\mathrm{D}_{\text {observed }}$ is the diffusion coefficient of the active in the presence of $C D$; $D_{\text {free }}$ is the diffusion coefficient of the active in the absence of $\mathrm{CD}$; $\mathrm{p}_{\text {complexed }}$ is the population fraction of completely complexed active, and $\mathrm{D}_{\text {complexed }}$ is the diffusion coefficient of the completely complexed.

Substituting the equation 3.19 in the equation 3.17, and considering that the diffusion of the active totally complexed is the same as the CD totally complexed and that the diffusion observed to the $\mathrm{CD}$ partially complexed is very close to the same free diffusion:

$$
D_{C D \text { complexed }} \approx D_{C D \text { observed free }} \approx D_{C D \text { free }}
$$

Substituting the equation 3.8 in the equation 3.5, p complexed $_{\text {can }}$ be obtained as:

$$
p_{\text {complexed }}=\frac{\mathrm{D}_{\text {free }}-\mathrm{D}_{\text {complexed }}}{\mathrm{D}_{\text {free }}-\mathrm{D}_{\text {CDobserved }}}
$$

Knowing $\mathrm{p}_{\text {complexed }}$ and the molar concentration of each species in solution, it is possible to obtain an estimative of the complex association constant $(\mathrm{Ka})$, if some precautions are taken account as: association constants in the order of 10-104 L/mol, the NMR observation and the solution concentration (Fielding, 2000). In our studies, one could observe that if the complex is sparkling soluble, more difficult is to acquire the DOSY data because the diffusion coefficients will have big errors.

The determination of association constants by DOSY provides an additional NMR method and an alternative of the chemical shift titration method (Simova \& Berger, 2005). The $\mathrm{K}_{\mathrm{a}}$ for a complex between the $\mathrm{n} \mathrm{mol} \mathrm{of} \mathrm{drug} \mathrm{D} \mathrm{and} \mathrm{m}$ mol of CD is (Rymdén et al., 1983).

$$
\begin{gathered}
n D+m C D \leftrightarrow \text { Complex }[\text { DnCDm }] \\
K a=\frac{[\text { Complex }]}{[D]^{n}[\text { CD }]^{m}}=\frac{[\text { Complex }]}{\left([D]_{0}-n[\text { Complex }]\right)^{n}\left([\text { CD }]_{0}-m[\text { Complex }]\right)^{m}}
\end{gathered}
$$


The equation 3.23 can be related with equation 3.21 , then:

$$
K_{a}=\frac{\boldsymbol{p}_{\text {complexed }}}{\left(1-\boldsymbol{p}_{\text {complexed }}\right)\left([C D]_{0}-\boldsymbol{p}_{\text {complexed }}[D]_{0}\right)}
$$

Fraceto et al. (Fraceto et al., 2007) applied DOSY to study the interaction between charged tetracaine in $\beta C D$ and p-sulphonic acid calix[6]arene, obtaining Ka 1,358 $\mathrm{M}^{-1}$ and 3,889 $\mathrm{M}^{-1}$,

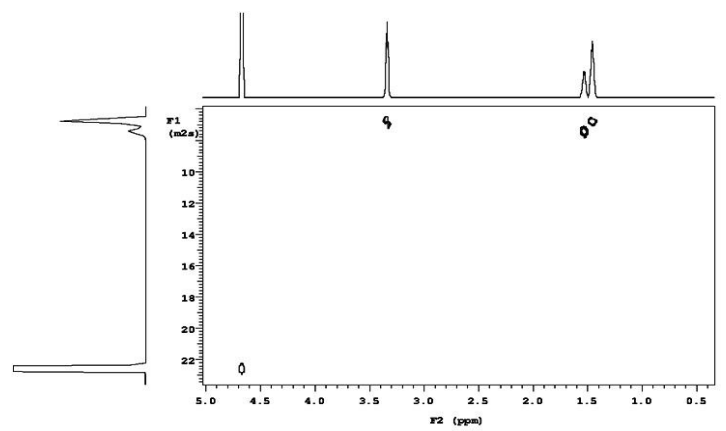

(a)

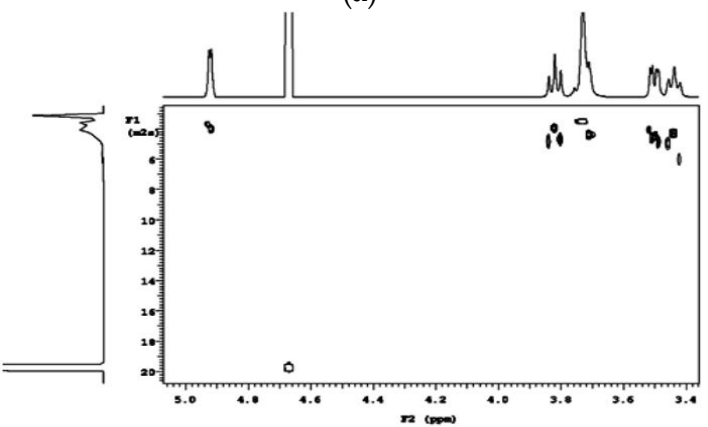

(b)

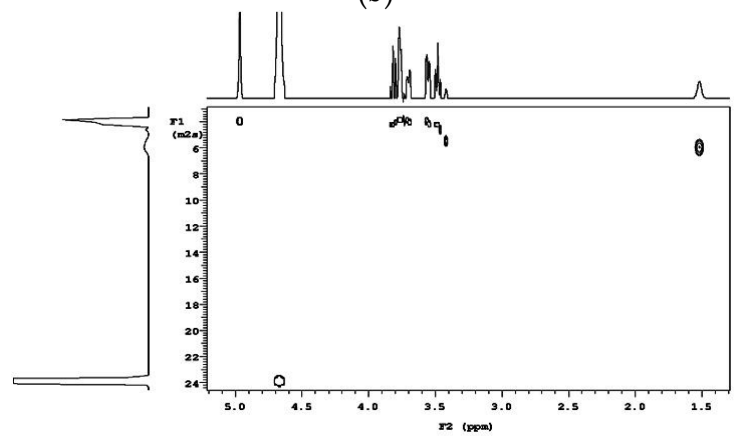

(c)

Fig. 9. ${ }^{1} \mathrm{H}-\mathrm{NMR}$ DOSY spectra. (a) MNX; (b) $\beta C D$; (c) NMX- $\beta C D$ 1:1, respectively $(500 \mathrm{MHz}$; $\left.\mathrm{D}_{2} \mathrm{O} ; \delta_{\mathrm{HOD}} 4.67 \mathrm{ppm}\right)$ 
respectively, indicating a good stability of the complexes. Jullian et al. (Jullian et al., 2007) studied the interaction between $(+)$ cathecin and natural and modified $\beta C D$ s observing a stronger interaction with natural $\beta C D$ than with hydroxipropil- $\beta C D$ or dimethyl- $\beta C D$, with association constants of $21,800 \mathrm{M}^{-1}, 13,580 \mathrm{M}^{-1}$ and $3,500 \mathrm{M}^{-1}$, respectively.

Besides the applicability of this technique to measure diffusion coefficients and association constants, DOSY experiments with cyclodextrins can be used with other techniques to predict enantiomeric discrimination (Laverde et al., 2002), to predict drug diffusion with polymeric CD (Bakkour et al., 2006), to conclude by the formation of conjugates with CDs, as for example the conjugate between $C D$ and folic acid, studied by Clementi et al. (Clementi et al., 2010), etc. In our group, the complexes of Minoxidil (MNX) and $\beta C D$ was investigated by DOSY using the pulse sequence GCSTESL (DOSY Gradient Compensated was Stimulated Echo with Spin Lock), 25 different amplitudes of pulse gradients in each experiment with the parameters $\mathrm{pw}=6.1 \mathrm{~s} ;$ at $=3.3 \mathrm{~s} ; \mathrm{d} 1=3.0 \mathrm{~s} ; \mathrm{nt}=32 ; \mathrm{lb}=0.2 \mathrm{~Hz}$. The spectra of MNX, $\beta C D$ and MNX: $\beta C D$ are shown in the Figure 9 and the data in Table 6.

\begin{tabular}{|c|c|c|c|c|}
\hline Complex & $\mathrm{D}_{\mathrm{MNX}}\left(1 \mathbf{1 0}^{-10} \mathrm{~m}^{2} \mathrm{~s}^{-1}\right)$ & $D_{C D}\left(10^{-10} m^{2} s^{-1}\right)$ & $\mathrm{D}_{\mathrm{OH}}\left(10^{-10} \mathrm{~m}^{2} \mathrm{~s}^{-1}\right)$ & $P_{\text {complexed }}(\%)$ \\
\hline MNX free & $6.363 \pm 0.019$ & --- & $22.538 \pm 0.087$ & --- \\
\hline$\alpha \mathrm{CD}$ & --- & $3.449 \pm 0.021$ & $23.366 \pm 0.017$ & \multirow{2}{*}{19.8} \\
\hline$\alpha 1: 1$ & $5.811 \pm 0.014$ & $3.581 \pm 0.006$ & $22.127 \pm 0.111$ & \\
\hline$\beta C D$ & --- & $3.254 \pm 0.024$ & $21.943 \pm 0.079$ & \multirow{2}{*}{91.4} \\
\hline$L \beta 1: 1$ & $3.565 \pm 0.058$ & $3.302 \pm 0.021$ & $23.935 \pm 0.118$ & \\
\hline$\gamma \mathrm{CD}$ & --- & $3.154 \pm 0.012$ & $22.082 \pm 0.105$ & \multirow{2}{*}{17.5} \\
\hline $\mathrm{L} \gamma 1: 1$ & $5.778 \pm 0.050$ & $3.014 \pm 0.033$ & $23.172 \pm 0.119$ & \\
\hline
\end{tabular}

Table 6. MNX diffusion coefficient ( $\mathrm{D}_{\mathrm{MNX}}$ ) free and in the presence of CDs, diffusion coefficient of $\alpha, \beta$ and $\gamma C D$ s and diffusion coefficients of water ( $\left.\mathrm{D}_{\mathrm{OH}}\right)$. Values of percentages of complexed MNX with CDs

It turns out that $\mathrm{D}$ of $\mathrm{HOD}$, free $\mathrm{CD}$ and MNX are quite different. Considering the size of the species in solution, the values are consistent, because the smaller hydrodynamic radius, the greater is tis coefficient. As expected, $\beta C D$ complexes are those with smaller diffusion coefficient and hence the largest population of complexed species, as the more complex the MNX is with the CDs, the lower its diffusion. Finally, it was also observed that these results have small errors.

DOSY was also employed to study the interaction between 5FU, a water soluble drug and the natural cyclodextrins. The diffusion coefficients data are in Table 7. It is evident that there are no interactions between the CDs and 5FU, as also observed by using other techniques.

\begin{tabular}{|c|c|c|c|c|}
\hline Sample & $\mathrm{D}_{5-\mathrm{FU}}\left(1 \mathbf{1 0}^{-10} \mathrm{~m}^{2} \mathrm{~s}^{-1}\right)$ & $\mathrm{D}_{\mathrm{CD}}\left(1 \mathbf{1 0}^{-10} \mathrm{~m}^{2} \mathrm{~s}^{-1}\right)$ & $\mathrm{D}_{\mathrm{OH}}\left(\mathbf{1 0}^{-10} \mathrm{~m}^{2} \mathrm{~s}^{-1}\right)$ & $\mathbf{P}_{\text {complexed }}(\%)$ \\
\hline $5 \mathrm{FU}$ & $9.216 \pm 0.028$ & --- & $22.538 \pm 0.087$ & --- \\
\hline$\alpha \mathrm{CD}$ & -- & $3.449 \pm 0.021$ & $23.366 \pm 0.017$ & \multirow{2}{*}{0} \\
\hline$\alpha 1: 1$ & $9.347 \pm 0.179$ & $3.353 \pm 0.146$ & $22.871 \pm 0.086$ & \\
\hline$\beta C D$ & -- & $3.254 \pm 0.024$ & $21.943 \pm 0.079$ & \multirow{2}{*}{0} \\
\hline L $\beta$ 1:1 & $9.338 \pm 0.295$ & $3.356 \pm 0.086$ & $22.879 \pm 0.087$ & \\
\hline
\end{tabular}

Table 7. Free 5FU diffusion coefficient ( $\left.D_{5 \mathrm{FU}}\right)$ and in the presence of $\mathrm{CDs}$, diffusion coefficient of $\alpha$ and $\beta C D$ s and diffusion coefficients of water $\left(\mathrm{D}_{\mathrm{OH}}\right)$. Values of percentages of complexed 5FU with CDs 
Studies were done on the complex involving the anti-helmintic drug thiabendazole (TBZ) and $\beta C D$. TBZ is a poor water soluble drug derived from benzimidazole with wide pharmacological, fungicide and bactericide applicability (Tang et al., 2005). It is believed that the enhancement of its water solubility can be achieved through formation of inclusion complexes with $\beta C D$. The data are in Table 8.

\begin{tabular}{|c|c|c|c|c|}
\hline Sample & $\mathrm{D}_{\mathrm{TBZ}}\left(1 \mathbf{1 0}^{-10} \mathrm{~m}^{2} \mathrm{~s}^{-1}\right)$ & $\mathrm{D}_{\mathrm{CD}}\left(\sqrt{10^{-10}} \mathrm{~m}^{2} \mathrm{~s}^{-1}\right)$ & $\mathrm{D}_{\mathrm{OH}}\left(\sqrt{10-10} \mathrm{~m}^{2} \mathrm{~s}^{-1}\right)$ & $P_{\text {complexed }}(\%)$ \\
\hline TBZ & $4.614 \pm 0.709$ & --- & $16.841 \pm 0.271$ & --- \\
\hline$\beta C D$ & --- & $2.513 \pm 0.038$ & $15.568 \pm 0.230$ & \multirow{2}{*}{18.4} \\
\hline $\mathrm{L} \beta 1: 1$ & $4.227 \pm 0.636$ & $2.243 \pm 0.019$ & $16.821 \pm 0.400$ & \\
\hline
\end{tabular}

Table 8. Free TBZ diffusion coefficient $\left(\mathrm{D}_{\mathrm{TBZ}}\right)$ free and in the presence of CDs, diffusion coefficient of $\beta C D$ and diffusion coefficients of water $\left(\mathrm{D}_{\mathrm{OH}}\right)$. Values of percentages of complexed TBZ with CDs

The values of $\mathrm{D}$ for free TBZ and for the drug in the 1:1 complex was not statistically different but the lower mean value for the complex indicates encapsulation of the molecules.

\subsection{The NOE experiments for structural characterization of CDs inclusion complexes: NOESY and ROESY}

When two nucleus, $\mathrm{HI}$ and HS, are closely situated $(\approx 4 \mathrm{~A})$, which can be in the same molecule or due to intermolecular forces, the local field existing in both nucleus will disturb each one, causing an dipole-dipole coupling that will have a null J-coupling (JIS $=0$ ). However it will change the spin-lattice relaxation time (T1) in the inter-nucleus environment. The dipoledipole coupling will cause splitting of the spin energy levels of both, HI and HS. When it occurs involving the nucleus of the same specie (as hydrogen nuclei), four new energy levels $(\alpha a, \alpha \beta, \beta a, \beta \beta)$, as in Figure 10 (Keeler, 2002).

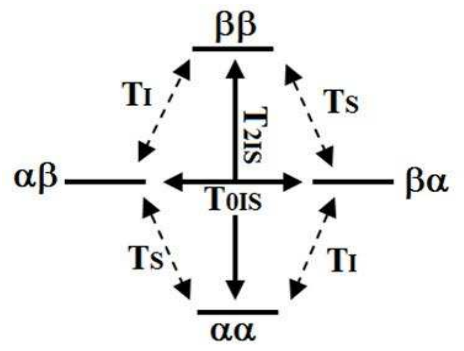

Fig. 10. Two homonuclear spin system energy levels diagram. $\mathrm{T}$ is respective transition occurrence probabilities. Spin states are shown for HI and HS nuclei, respectively

NOE can be defined as the change of the HI resonance intensity when HS resonance is perturbed. This can be probed applying a selective pulse into this nucleus (RF pulse applied has the same frequency as the HI Larmour frequency). Due to the dipolar coupling, this change is related to the population transition between the energy levels. While these transitions cannot be induced by another RF pulse, they can occur in the dipolar relaxation process. Initially, only a $\alpha$ and $\beta \beta$ spin energy levels are populated; however, when applying a selective pulse, all the levels become equally populated, but no change on resonance 
intensity in both HI and HS is observed. When the selective pulse in HS is ended, the reequilibrium will occurs through dipolar relaxation, according to the transitions probability TOIS and T2IS or TI/TS, (the last ones are isolated from each nucleus and, therefore, will not cause NOE), during a specific time (mixing time). The relaxation through the transition probability T2IS will increase the HI resonance intensity (positive NOE), and the one that occurs through TOIS will result in decrease of HI resonance (negative NOE) (Neuhaus \& Williamson, 1989).

NOE measurements can be done in both steady and dynamic states. In the steady-state, HS is irradiated with a weak and continuum RF field that does not affect HI spin, until its resonance become saturated. Then, the NOE enhancement over HI is measured as the difference of its resonance intensities under HS saturation and when this condition is not applied (system in equilibrium). In the dynamic NOE measurement (NOESY, Nuclear Overhauser Enhancement SpectroscopY) HS resonance will not be saturated during the mixing time, and the NOE enhancement will depend to both nuclei magnetization amplitudes after the evolution period 11 (Figure 2). The main difference in the NOESY experiment is that the NOE enhancement intensity will be describe as three different peaks in a 2D-spectrum which can discriminate HI-HS cross-peak correlation from peaks related to other changes on HS resonance. The pulse sequences for each experiment are those reported by Keeler (Keeler, 2002).

ROESY (Rotational Overhauser Enhancement SpectroscopY) experiment was firstly developed by Bothner-By et al. (Bothner-By et al., 1984), as an alternative methodology to study NOE, and it can be done in one or two dimensions. The 1D experiment was named CAMELSPIN (Cross-relaxation Apropriate for Mini-molecules EmuLated by SPIN-locking).

The main advantage of the ROESY experiment over the traditional NOESY is the use of the spin-lock condition, that is done applying of a strong, constant and coherent pulse at HS Larmour frequency throughout the mixing time. This pulse will saturate the HS resonance (magnetization vectors projections stays precessing in the $X Y$ plane), and then, the rOe (rotational Overhauser effect) will not only be enhanced due the longitudinal magnetization components interactions, but also due to the interactions of transversal ones. The main consequence will be a positive rOe condition over all molecules. The NOE signal will be enhanced even for molecules whose $w . t c\left(w\right.$ is the Larmour frequency and $t_{c}$ is the rotational correlation time) product is small, in contrast to NOESY, wherein small $t_{c}$ results on negative nOe (Neuhaus \& Williamson, 1989). As this small w.t $t_{c}$ condition exist on NOE measurements of CD inclusion complexes, the ROESY experiment become suitable for structural study of these systems (Schneider et al., 1998).

Both NOESY and ROESY experiments have been widely applied for structural elucidation of guest:CD inclusion complexes, which are done through the internuclear NOE enhancement measures between the guest nuclei and the CD inner cavity nuclei H3, H5 and H6. Besides, NOE cross-peaks can be correlated to their respective internuclear distances (Evans, 1995; Pinto et al., 2005). Therefore more detailed information about the supramolecular organization of these systems can also be obtained beyond just qualitative structural analysis as with the changes in chemical shift.

NOE-based experiments are generally done in two-dimensions, as all cross-peak correlations can be seen in the spectrum, becoming easier the interpretation of the data. In 
the 1-D version, the experiment must be done separately by applying the selective pulses for each nucleus, obtaining the corresponding spectrum, which turn this experiment usually more time requesting. However 1D experiment has more sensibility, which can be necessary if detection of weak NOE interactions or complex limited solubility is involved.

The literature reports several NOESY and ROESY experiments, and some examples will be commented. An extent characterization of CDs inclusion complexes with different terpenes employing NMR based on ${ }^{1} \mathrm{H}$ and ${ }^{13} \mathrm{C}$ chemical shifts analyses $(\Delta \delta)$ and 2D-ROESY was reported by Bergonzi et al. (Bergonzi et al., 2007).

Interactions involving the steroids prednisolone, ethinyloestradiol and estriol with $\beta C D$ were studied by the NOE-based and chemical shift analysis NMR experiments (Bednarek et al., 2002). The authors could distinguish steroids affinities with $\beta C D$ through their different penetration into the CD cavity.

Inclusion complex between the drug Tenoxican and $\beta C D$ was also characterized by ROESY2D experiment (Voulgari et al., 2007) and drug molecular dimerization was studied by NOESY, showing that further description of these systems can be obtained with different NMR different experiment.

Another very interesting application of NOE-based experiments on CDs inclusion complexes provides structure elucidation between enantiomers and CDs. With the 1DROESY experiment, interactions between Aminoglutethimide (Elbashir et al., 2009) and propranolol (Servais et al., 2010) enantiomers with CDs could have been separately characterized. This kind of study was also done with ROESY-2D experiment for vinca alkaloids enantiomers (Sohajda et al., 2010). In a recent work, de Paula et al. explored 1DROESY for studying interactions involved on ternary systems of Prilocaine-cyclodextrinliposome (Cabeça et al., 2011) and propracaine- $\beta$ CD-liposome (Cabeça et al., 2008), obtaining information on the topology of the inclusion complex inside the liposome membrane.

\subsection{Solid state NMR}

${ }^{13} \mathrm{C}$-Cross Polarization Magic Angle Spinning (CPMAS) NMR is other technique used to study interactions between drugs and cyclodextrins (Schneider et al., 1998). Also CPMAS measurements provides a powerful non-invasive approach to the molecular analysis of starch-related structures, its cyclodextrin characterization provides information on the molecular organization at shorter distance scales (Gidley \& Bociek, 1988). However, this study is more complex and fails when some drug characteristics are not obey, as it will be shown.

The spectra of solids in normal conditions are broad and unresolved, providing restricted information. This phenomenon happens because not only the indirect spin-spin interaction between nuclei through bonds takes place, but also the nuclear magnets can couple through the direct interaction of their nuclear dipoles, in order of $10^{2}-10^{4} \mathrm{~Hz}$. This effect can be eliminated by applying a strong magnetic field perpendicular to the magnetic field $B_{0}\left(B_{2}\right)$. Other factor is the chemical shielding anisotropy, which are in the order of 103-104 Hz, due to the shielding of a specific nucleus in a time to record because the nuclei have to be allowed to relax for several minutes between pulses. This factor was solved by a process 
called Cross Polarization (CP). It takes advantage of the properties of the protons coupled to the carbons, as the double irradiation process $\left(\mathrm{B}_{0}\right.$ and $\left.\mathrm{B}_{2}\right)$ is used to transfer some of the proton's faster relaxation and higher magnetization to the carbon atoms (Lambert \& Mazzola, 2004; Saito et al., 2006).

When the protons move onto the $x$-axis by a $90^{\circ}$ pulse, a continuous y field is applied, which intensity is controlled in the equipment, to keep the magnetization precessing in that axis (spin locking). As soon as the ${ }^{13} \mathrm{C}$ channel is turned on, the Hartmann-Hann condition is set, i.e. ${ }^{13} \mathrm{C}$ frequency become equal to the ${ }^{1} \mathrm{H}$ frequency. In this situation all nuclei precess at the same frequency and magnetization, turning the ${ }^{13} \mathrm{C}$ higher than in normal pulse experiments, enhancing the carbon resonances and the relaxation. Finally, at the maximum intensity, the magnetic field of the ${ }^{13} \mathrm{C}$ channel is turned off and the carbon magnetization is acquired (Lambert \& Mazzola, 2004).

However, broad line widths and spectra of compounds with many non-equivalent nuclei are difficult to analyze due to the strong overlap even if the contributions of dipolar ${ }^{1} \mathrm{H},{ }^{13} \mathrm{C}$ coupling are practically eliminated. So, a technique is used to observe high resolution spectra, where the sample cell is rotated around the magic angle (MAS = Magic Angle Spinning). In this experiment, the rotor is rotated with a high spinning rate around an axis which makes the magic angle of $\theta=54.7^{\circ}$ with the axis of the external field $B_{o}$ in order to vanish the chemical shift anisotropy. So, combining the MAS technique with the $\mathrm{CP}$ technique is possible to narrow the resonance lines and obtain the CPMAS spectra (Günter, 1994).

The confirmation of the inclusion complex between molecules and CDs is doing analyzing the differences in the chemical shifts and modification of the peaks between the free and complexed guest molecules. The appearance of multiple resonances for atoms C2, C3, C5, C4, and C6 of the glucopyranose units indicates the coexistence of different structural arrangements (Lima, 2001). Usually, the multiple resonances of the carbons of the glucose monomers tends to converge to a single peak in the inclusion compound, suggesting that the glucose units adopt a more symmetrical conformation in the complex (Lai et al., 2003). However, one has to take care in this analysis since this phenomenon can also be due to the freeze-drying process, which leads to amorphization of the sample, not indicating the hostguest interaction (Figure 11).

The imazalil : $\beta C D$ complex was prepared using supercritical carbon dioxide and was characterized by CPMAS by Lai et al. The authors realized not only the conformation changing between the spectra of inclusion compound and physical mixture, but also changes in chemical shift, a marked broadening of all signals, and that several resonances of imazalil split up into multiple signals, indicative of a pronounced structural rearrangement of the imidazole and aryl rings (Lai et al., 2003) inside the CD cavity.

This technique is applied to confirm the inclusion between the CDs and polymers, as poly( $(\varepsilon-$ caprolactone) (Harada et al., 2007), comblike poly(ethylene oxide) grafted polymers (He et al., 2005) and poly(e-lysine) (Huh et al., 2001). In these studies, they usually compared the spectrum of the complex with the physical mixture, showing that the CD molecule retain a less symmetrical cyclic conformation in the crystalline uncomplexed state, characterized by resolved $\mathrm{C} 1$ and $\mathrm{C} 4$ resonances of the glucose units, comparing with the $\mathrm{CD}$ in the complexed state, which has a symmetrical cyclic conformation. 


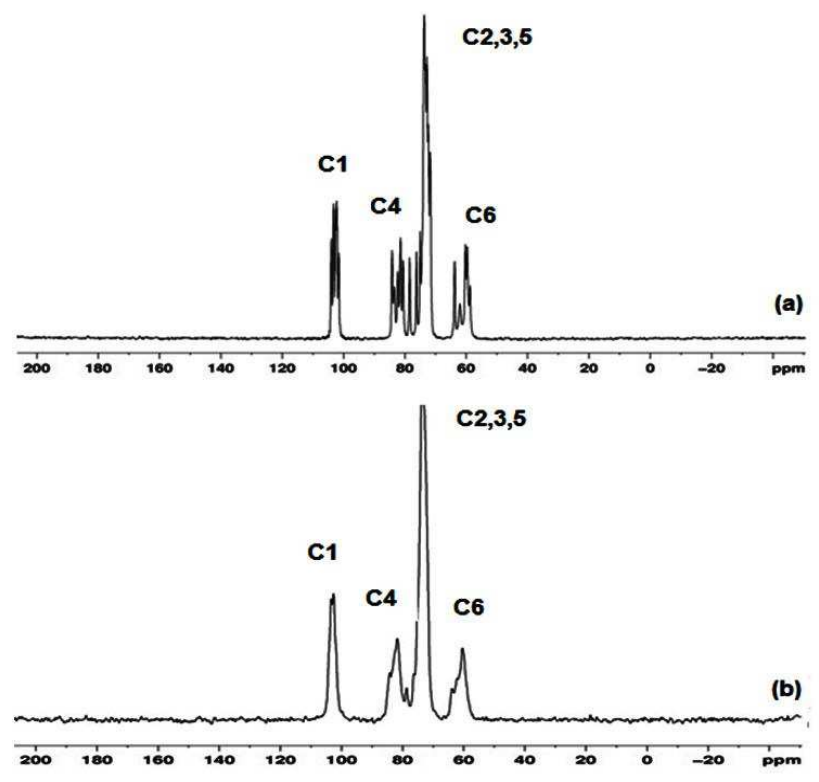

Fig. 11. ${ }^{13} \mathrm{C}$ - CPMAS NMR spectra. (a) natural; (b) freeze-dried $\beta C D(10 \mathrm{kHz}, 298 \mathrm{~K})$

One of the inclusion complex analyzed in our laboratory was Dapsona (DPS) and HPhydroxypropyl- $\beta C D$. DPS (4,4'diaminodiphenylsulfone) is a very effective drug to treat leprosy and inflammatory conditions in Pneumocystis carinii pneumonia, toxoplasmosis and tuberculosis. However, the oral administration of this drug leads to serious side effects and treatment failures. It is believed that the complex DPS:HP- $\beta C D$ would increase the wettability and the solubility of this drug for a supported and gradual release, maximizing its biodisponibility over time (Wozel et al., 1997; Chougule et al., 2008). The spectra of DPS, HP- $\beta C D$, the physical mixture and the inclusion compound are in the Figures 12-15.

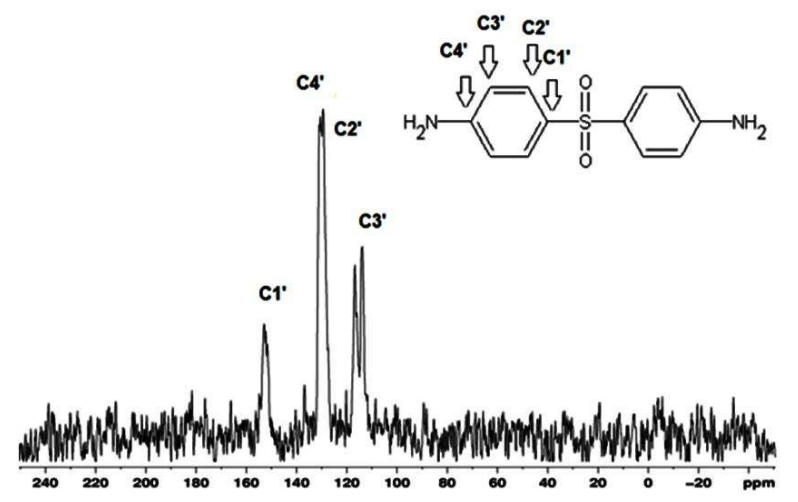

Fig. 12. ${ }^{13} \mathrm{C}-\mathrm{CPMAS}$ NMR spectra of DPS $(10 \mathrm{kHz}, 298 \mathrm{~K})$ 


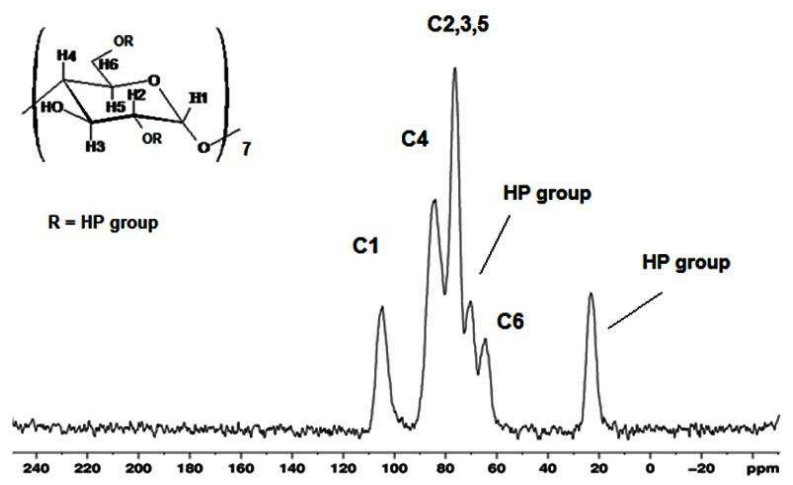

Fig. 13. ${ }^{13} \mathrm{C}$ - CPMAS NMR spectra of HP- $\beta C D(10 \mathrm{kHz}, 298 \mathrm{~K})$

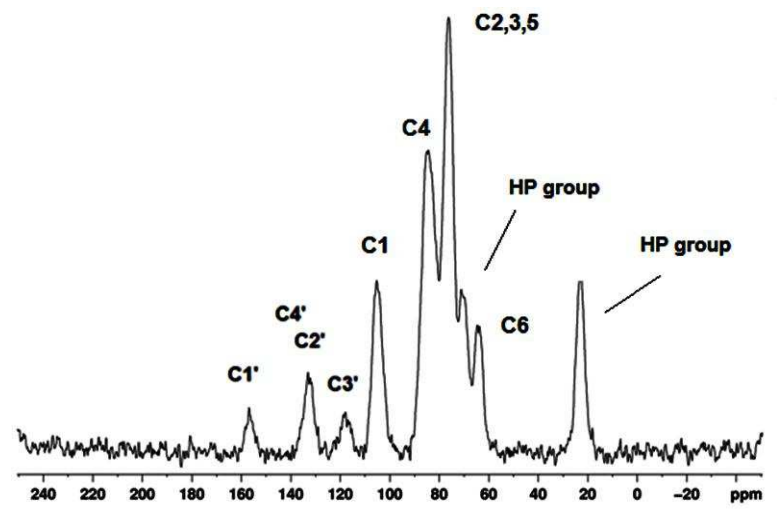

Fig. 14. ${ }^{13} \mathrm{C}-\mathrm{CPMAS} N M R$ spectra of DPS :HP- $\beta C D:(10 \mathrm{kHz}, 298 \mathrm{~K})$

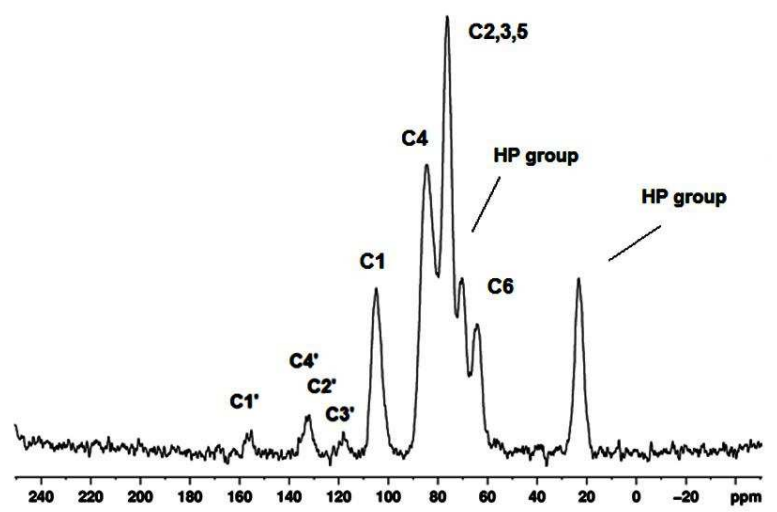

Fig. 15. ${ }^{13} \mathrm{C}-\mathrm{CPMAS}$ NMR spectra of DPS and HP- $\beta C D$ physical mixture $(10 \mathrm{kHz}, 298 \mathrm{~K})$

The ${ }^{13} \mathrm{C}$ chemical shifts for $\beta C D$, DPS, physical mixtures and complex are in the Tables 9-12. 


\begin{tabular}{|c|c|c|c|}
\hline C & $\delta_{\mathrm{HP}-\beta \mathrm{CD}}$ & $\delta_{\text {DPS:HP- } \beta C D / P M}$ & $\Delta\left(\delta_{\text {DPS:HP- } \beta C D}-\delta_{\text {HP- } \beta \mathrm{CD}}\right)$ \\
\hline C1 & 104.7 & 104.9 & 0.2 \\
\hline $\mathrm{C} 2,3,5$ & 76.3 & 76.3 & 0 \\
\hline C4 & 84 & 84.7 & 0.7 \\
\hline C6 & 64.3 & 64.3 & 0 \\
\hline HP-group & $70.1 ; 23.2$ & $70.3 ; 23.2$ & $0.2 ; 0$ \\
\hline
\end{tabular}

Table 9. ${ }^{13} \mathrm{C}$-CPMAS NMR chemical shifts of $\beta C D$ and their change in the presence of DPS in the physical mixture $\left(\Delta \delta=\delta_{\mathrm{PM}}-\delta_{\text {free }}\right)$

\begin{tabular}{|c|c|c|c|}
\hline $\mathbf{C}$ & $\boldsymbol{\delta}_{\text {HP- } \beta \mathrm{CD}}$ & $\boldsymbol{\delta}_{\text {DPS:HP- } \beta \mathrm{CD}}$ & $\Delta\left(\boldsymbol{\delta}_{\mathrm{DPS}: \beta \mathrm{CD}}-\boldsymbol{\delta}_{\text {HP- } \beta \mathrm{CD}}\right)$ \\
\hline $\mathbf{C 1}$ & 104.7 & 105.3 & 0.6 \\
\hline $\mathbf{C 2 , 3 , 5}$ & 76.3 & 76.2 & 0.1 \\
\hline $\mathbf{C 4}$ & 84 & 84.5 & 0.5 \\
\hline $\mathbf{C 6}$ & 64.3 & 64.2 & 0.3 \\
\hline HP-group & $70.1 ; 23.2$ & $71.2 ; 22.9$ & $1.1 ; 0.3$ \\
\hline
\end{tabular}

Table 10. ${ }^{13} \mathrm{C}$-CPMAS NMR chemical shifts of HP- $\beta C D$ and their change in the in the complex $\left(\Delta \delta=\delta_{\text {complexed }}-\delta_{\text {free }}\right)$

\begin{tabular}{|c|c|c|c|}
\hline $\mathbf{H}$ & $\delta_{\text {DPS }}$ & $\delta_{\text {DPS HP- } \beta C D / P M}$ & $\Delta\left(\delta_{\text {DPS:HP- } \beta C D / P M}-\delta_{\text {HP- } \beta C D}\right)$ \\
\hline $\mathrm{C} 1^{\prime}$ & 152.8 & 153.9 & 1.1 \\
\hline $\mathrm{C} 2,4^{\prime}$ & 130 & 131.9 & 1.9 \\
\hline C3' & 115.5 & 116 & 0.5 \\
\hline
\end{tabular}

Table 11. ${ }^{13} \mathrm{C}-\mathrm{CPMAS}$ NMR chemical shifts of DPS and their change in the presence of $\beta C D$ in the physical mixture $\left(\Delta \delta=\delta_{\mathrm{PM}}-\delta_{\text {free }}\right)$

\begin{tabular}{|c|c|c|c|}
\hline $\mathbf{H}$ & $\boldsymbol{\delta}_{\mathrm{DPS}}$ & $\boldsymbol{\delta}_{\mathrm{DPS}: \mathrm{HP}-\beta \mathrm{\beta CD}}$ & $\Delta\left(\boldsymbol{\delta}_{\mathrm{DPS}: \beta \mathrm{CD}}-\boldsymbol{\delta}_{\mathrm{HP}-\boldsymbol{\beta C D}}\right)$ \\
\hline $\mathrm{C} 1^{\prime}$ & 152.8 & 156.9 & 4.1 \\
\hline $\mathrm{C} 2,4^{\prime}$ & 130 & 133.1 & 3.1 \\
\hline $\mathrm{C}^{\prime}$ & 115.5 & 118 & 2.5 \\
\hline
\end{tabular}

Table 12. ${ }^{13} \mathrm{C}-\mathrm{CPMAS}$ NMR chemical shifts of DPS and their variation in the presence of HP$\beta C D$ in the complex $\left(\Delta \delta=\delta_{\text {complexed }}-\delta_{\text {free }}\right)$

When DPS is complexed with HP- $\beta C D \Delta \delta$ is higher than in the physical mixture. Also, there is a peak broadening in the inclusion complex spectrum. As discussed before, both facts suggest that DPS is encapsulated into the cyclodextrin cavity and interacting with the hydroxypropyl group. Moreover, although it is observed a $\Delta \delta$, one can clearly note that the spectrum of the physical mixture is a combination of the spectrum of HP- $\beta C D$ and of DPS.

\section{Experimental}

\subsection{Materials and methods}

Dapsone was supplied by Ecofarma Farmácia Ltda.; Minoxidil by Galderma Brasil S.A.; Thiabendazole by EMS; $\alpha, \beta$ and $\gamma$ CD were supplied by Amaizo (American Maize-Products 
Co.); hydroxypropyl- $\beta C D$ and $\beta C D$ were gifts from ISP Technologies, Inc.; ethyl alcohol 99.5\% P.A. was purchased from LabSynth Ltda. Products for Laboratories; $99.9 \%$ deuterium oxide was purchased from Cambridge Isotope Laboratories, Inc.; Freeze-dryer FTS Systems; Bruker Avance II $300 \mathrm{MHz}$ and Varian $500 \mathrm{MHz}$ NMR spectrometers; rotary evaporator RE111, water bath 461 and vacuum pump Büchi Labortechnik AG.

\subsection{Preparation of inclusion complex}

The inclusion complexes were prepared by one of the two method, co-precipitation or freeze-drying, in an equimolar stoichoimetry.

\subsection{Preparation of physical mixtures (PM)}

Physical mixtures were prepared using the molar ratio of $\mathrm{CD}$ and drug by simply mixing the two compounds for $2 \mathrm{~min}$.

\subsection{NMR spectroscopy experiments}

All experiments with liquid samples were run on a Varian INOVA-500 spectrometer $(\mathrm{BO}=$ $11 \mathrm{~T}$ ), operating at $500 \mathrm{MHz}$ for ${ }^{1} \mathrm{H}$. The temperature was kept at $297.6 \pm 0.1 \mathrm{~K}$ in all experiments. The chemical shifts were referenced against the HOD resonance $(\delta 4.67 \mathrm{ppm})$. The samples were prepared by dissolving of $2-4 \mathrm{mg}$ of the FD complex in $\approx 0.6 \mathrm{~mL}$ of $\mathrm{D}_{2} \mathrm{O}$. The signal of the solvent was used to stop the magnetic field and the radio frequency. The data were acquired using standards Varian software in the following conditions and processed using the program VNMR of the equipment. To obtain the ${ }^{1} \mathrm{H}$ NMR spectra the conditions were: pw $6.1 \mathrm{~s}$; at $3.3 \mathrm{~s}$; d1 $3.0 \mathrm{~s} ; \mathrm{nt} 32 \mathrm{scans} ; \mathrm{lb} 0.2 \mathrm{~Hz}$.

DOSY: The pulse sequence for DOSY was GCSTESL (DOSY Gradient Compensated Stimulated Echo with Spin Lock). In all analyses 25 different pulsed gradient amplitudes were: d1 $6.1 \mathrm{~s}$; at $3.3 \mathrm{~s}$; nt 32 scans; $1 \mathrm{lb} 0.2 \mathrm{~Hz}$.

T1 measurement: For ${ }^{1} \mathrm{H}-\mathrm{NMR}$, a $90^{\circ}$ pulse was typically of $15 \mu \mathrm{s}$, and the recycling time was set to $15 \mathrm{~s}$. Longitudinal relaxation times were obtained by the conventional inversionrecovery method.

ROESY: The ROESY experiment was carried out using the parameters: at $1.0 \mathrm{~s}$; d1 $3.0 \mathrm{~s}$; nt 1024 scans; lb $1.0 \mathrm{~Hz}$. The data was obtained applying a sequence of pulses $180^{\circ}$ sel. $-90^{\circ}$ sel. - spin lock-FID, mixing time of $500 \mathrm{~ms}$. FIDs were acquired through the sequence of pulses $90^{\circ}$ sel. - spin lock - FID. A modulator generated the selective pulses and automatically attenuated the power and duration of the pulse.

${ }^{13}$ C-CPMAS: All spectra of ${ }^{13} \mathrm{C}-\mathrm{CPMAS}$ of lyophilized samples, physical mixtures, drugs and CDs were run on a Bruker $300 \mathrm{MHz}$ at $298 \mathrm{~K}$ and $10 \mathrm{kHz}$.

\section{Conclusion}

NMR is one of the most powerful techniques to investigate interactions between guest and cyclodextrins molecules as it gives extremely useful information on physico-chemical parameters, orientation of the guest molecule inside the cavity and the complex stability. 


\section{Acknowledgment}

The authors gratefully acknowledge financial support from CAPES and CNPq, the ISP Technologies, Inc. for supplying $\beta C D$ Sônia Fanelli and Anderson S. Pedrosa for assistance with the NMR work and Milene H. Martins for her cooperation with the Dapsone experiments.

\section{References}

Bakkour, Y., Vermeersch, G., Morcellet M., Boschini, F., Martel, B. \& Azaroual, N. (2006). Formation of cyclodextrin inclusion complexes with doxycyclin-hydrate: NMR investigation of their characterization and stability. Journal of Inclusion Phenomena and Macrocyclic Chemistry, Vol. 54, $\mathrm{N}^{\circ}$ 1-2, (April 2005), pp. 109-114, DOI 10.1007/s10847-005-5108-7

Bayomi, S.M. \& Al-Badr, A.A. 5-Fluorouracil, In: Analytical Profiles of Drug Substances. Florey, K. (Ed.). (1990). Vol. 18, pp. 599-639, Academic Press, ISBN: 978-0-12260819-3, New York, USA, DOI 10.1016/S0099-5428(08)60682-6

Bednarek, E., Bocian, W., Poznański, J., Sitkowski, J., Sadlej-Sosnowska, N. \& Kozerski, L. (2002). Complexation of steroid hormones: prednisolone, ethinyloestradiol and estriol with $\beta$-cyclodextrin. An aqueous ${ }^{1} \mathrm{H}$ NMR study. Journal of Chemical Society Perkin Transactions, Vol. 2, Issue 5, (April 2002), pp. 999-1004, DOI 10.1039/B110435G

Bergeron, R.J. (1977). Cycloamyloses. Journal of Chemical Education, Vol. 54, Issue 4, (April 1977), pp. 204-207, DOI 10.1021/ed054p204

Bergonzi, M.C., Bilia, A.R., Di Bari, L., Mazzi, G. \& Vincieri, F.F. (2007). Studies on the interactions between some flavonols and cyclodextrins. Bioorganic $\mathcal{E}$ Medicinal Chemistry Letters, Vol. 17, Issue 21, (November 2007), pp. 5744-5748, DOI 10.1016/j.bmcl.2007.08.067

Bothner-By, A.A., Stephens, R.L., Lee, J., Warren, C.D. \& Jeanloz, R.W. (1984). Structure determination of a tetrasaccharide: transient nuclear Overhauser effects in the rotating frame. Journal of American Chemical Society, Vol. 106, Issue 3, (February 1984), pp. 811-813, DOI 10.1021/ja00315a069

Buschmann H.-J. \& Schollmeyer E. (2002). Applications of cyclodextrins in cosmetic products: A review. Journal of Cosmetic Science, Vol. 53, (May/June 2002), pp. 185-191

Cabeça, S.A., Figueiredo, I.M., de Paula, E. \& Marsaioli, A.J. (2011). Prilocaine-cyclodextrinliposome: effect of $\mathrm{pH}$ variations on the encapsulation and topology of a ternary complex using ${ }^{1} \mathrm{H}$ NMR. Magnetic Resonance in Chemistry, Vol. 49, Issue 6, (June 2011), pp. 295-300, DOI 10.1002/mrc. 2740

Cabeça, S.A., Fraceto, L.F., Marsaioli, A.J. \& de Paula, E. (2007). Investigation of tetracaine complexation with beta-cyclodextrins and p-sulphonic acid calix[6]arenes by nOe and PGSE NMR. Journal of Inclusion Phenomena and Macrocyclic Chemistry, Vol. 57, N 1-4, (February 2007), pp. 395-401, DOI 10.1007/s10847-006-9224-9

Casu, B., Reggiani, M., Gallo, G.G. \& Vigenvani, A. (1966). Hydrogen bonding and conformation of glucose and polyglucoses in dimethyl-sulphoxide solution Tetrahedron, Vol. 22, Issue 9, (June 1966), pp. 3061-3083, DOI 10.1016/S0040-4020(01)82286-9

Casu, B., Reggiani, M., Gallo, G.G., Vigenvani, A. (1968). Conformation of O-methylated amylose and cyclodextrins. Tetrahedron, Vol. 24, Issue 2, (June 1968), pp. 803-821, DOI 10.1016/0040-4020(68)88030-5

Chen, G. \& Jiang, M. (2011). Cyclodextrin-based inclusion complexation bridging supramolecular chemistry and macromolecular self-assembly. Chemical Society Review, Vol. 40, (February 2011), pp. 2254-2266, DOI 10.1039/c0cs00153h 
Chougule, M., Padhi, B. \& Misra, A. (2008). Development of spray dried liposomal dry powder inhaler of Dapsone. AAPS PharmSciTech., Vol. 9, N 1, (January 2008), pp. 47-55, DOI 10.1208/s12249-007-9024-6

Clementi, A., Aversa, M. C., Corsaro, C., Spooren, J., Stancanelli, R., O'Connor, C., McNamara, M. \& Mazzaglia, A. (2010). Synthesis and characterization of a colloidal novel folic acid- $\beta$-cyclodextrin conjugate for targeted drug delivery, Articles, Paper 2, (January 2010), http:/ / arrow.dit.ie/materart/2, accessed in August 2011

Connors, K.A. (1997). The stability of cyclodextrin complexes in solution. Chemical Reviews, Vol. 97, Issue 5, (August 1997), pp. 1325-1358, DOI 10.1021/cr960371r

Elbashir, A.A., Suliman, F.E.O., Saad, B. \& Aboul-Enein, H.Y. (2009). Determination of aminoglutethimide enantiomers in pharmaceutical formulations by capillary electrophoresis using methylated- $\beta$-cyclodextrin as a chiral selector and computational calculation for their respective inclusion complexes. Talanta, Vol. 77, Issue 4, (February 2009), pp. 1388-1393, DOI 10.1016/j.talanta.2008.09.029

Evans, J.N.S. (1995). Biomolecular NMR spectroscopy. Oxford University Press, ISBN-10 0198547668, ISBN-13 978-0198547662, Oxford, England.

Fielding, L. (2000). Determination of association constants $\left(\mathrm{K}_{\mathrm{a}}\right)$ from solution NMR data. Tetrahedron, Vol. 56, Issue 34, (May 2000), pp. 6151-6170, DOI 10.1016/S00404020(00)00492-0, ISSN 00404020

Foster, R. \& Fyfe, C.A. (1965a). Interaction of electron acceptors with bases. Part 15.Determination of association constants of organic charge-transfer complexes by n.m.r. spectroscopy. Transactions of Faraday Society, Vol. 61, (February 1965), pp. 1626-1631, DOI 10.1039/TF9656101626

Foster, R. \& Fyfe, C.A. (1965b). Fluorine nuclear magnetic resonance determination of the association constant of an organic electron-donor-acceptor complex. Chemical Communications (London), Vol. 61, Issue 24, (November 1965), pp. 642-642, DOI 10.1039/C19650000642

Fraceto, L.F., Cabeça, S.A., de Paula, E. \& Marsaioli, A.J. (2008). Topology of a ternary complex (propracaine- $\beta$-cyclodextrin-liposome) by STD NMR. Magnetic Resonance in Chemistry, Vol. 46, Issue 9, (September 2008), pp. 832-837, DOI 10.1002/mrc.2265

Friebolin, H. (1993). Basic one- and two-dimensional NMR spectroscopy. (2nd ed.). VHC, ISBN 156081-796-8, New York, USA.

Gidley, M.J. \& Bociek, S.M. (1998). ${ }^{13}$ C CPMAS NMR studies of amylose inclusion complexes, cyclodextrins, and the amorphous phase of starch granules: relationships between glycosidic linkage conformation and solid-state ${ }^{13} \mathrm{C}$ chemical shifts. Journal of American Chemical Society, Vol. 110, N 12, (June 1998), pp. 38203829, DOI 10.1021/ja00220a016

Gorecki, D.K.J. Minoxidil, In: Analytical Profiles of Drug Substances. Florey, K. (Ed.). (1988). Vol. 17, pp. 185-219, Academic Press, ISSN: 0099-5428, New York, USA, DOI 10.1016/S0099-5428(08)60220-8

Greatbanks, D. \& Pickford, R. (1987). Cyclodextrins as chiral complexing agents in water, and their application to optical purity measurements. Magnetic Resonance in Chemistry, Vol. 25, N³, (March 1987), pp. 208-215, DOI 10.1002/mrc.1260250306

Griffiths, D.W. \& Bender, M.L. (1973). Orientational catalysis by cyclohexaamylose. Journal of the American Chemical Society, Vol. 95, (March 1973), pp. 1679-1680, DOI 10.1021/ja00786a064

Grillo, R., Melo, N.F.S., Moraes, C.M., Rosa, A.H., Royeda, J.A.F.R., Menezes, C.M.S., Ferreira, E.I.F. \& Fraceto, L.F. (2007). Hydroxymethylnitrofurazone:dimethyl- $\beta$-cyclodextrin 
inclusion complex: a physical-chemistry characterization. Journal of Biological Physics, Vol. 33, N 5-6, (December 2007), pp. 445-453, DOI 10.1007/s10867-008-9054-7

Günter, H. (1994). NMR spectroscopy: basic principles, concepts and applications in chemistry. (2nd ed.). John Wiley \& Sons, ISBN 0-471-95199-4, Chichester, England

Hanna, M.W. \& Ashbaugh, A.L. (1964). Nuclear Magnetic Resonance study of molecular complexes of 7,7,8,8-tetracyanoquinodimethane and aromatic donors. Journal of Physical Chemistry, Vol. 68, Issue 4, (April 1964), pp. 811-816, DOI 10.1021/j100786a018

Harada, A., Kawaguchi, Y., Nishiyama, T. \& Kamachi, M. (1997). Complex formation of poly(e-caprolactone) with cyclodextrin. Macromolecular Rapid Communications, Vol. 18, N 7, (July 1997), pp. 535-539, DOI 10.1002/marc.1997.030180701

He, L., Huang, J., Chen, Y. \& Liu, L. (2005). Inclusion complexation between comblike PEO grafted polymers and a-cyclodextrin. Macromolecules, Vol. 38, No 8, (March 2005), pp. 3351-3355, DOI 10.1021/ma047748c

Hoarea, T.R. \& Kohaneb, D.S. (2008). Hydrogels in drug delivery: progress and challenges. Polymer, Vol. 49, Issue 8, (April 2008), pp. 1993-2007, DOI 10.1016/j.polymer.2008.01.027

Huh, K.M., Ooya, T., Sasaki, S. \& Yui, N. (2001). Polymer inclusion complex consisting of poly(E-lysine) and alfa-cyclodextrin. Macromolecules, Vol. 34, N 8, (March 2001), pp. 2402-2404, DOI 10.1021/ma0018648

Jullian, C., Miranda, S., Zapata-Torres, G., Mendizábal, F. \& Olea-Azar, C. (2007). Studies of inclusion complexes of natural and modified cyclodextrin with $(+)$ catechin by NMR and molecular modeling. Bioorganic \& Medicinal Chemistry, Vol. 15, Issue 9, (May 2007), pp. 3217-3224, DOI 10.1016/j.bmc.2007.02.035

Keeler, J. (2005). Understanding NMR Spectroscopy. Wiley Inc., ISBN 13 978-0-470-01787-6 (P/B), Chichester, England.

Lai, S., Locci, E., Piras, A., Porcedda, S., Lai, A. \& Marongiu, B. (2003). Imazalilcyclomaltoheptaose ( $\beta$-cyclodextrin) inclusion complex: preparation by supercritical carbon dioxide and ${ }^{13} \mathrm{C}$ CPMAS and ${ }^{1} \mathrm{H}$ NMR characterization. Carbohydrate Research, Vol. 338, Issue 21, (October 2003), pp. 2227-2232, DOI 10.1016/S0008-6215(03)00358-6

Lambert, J.B. \& Mazzola, E.P. (2004). Nuclear Magnetic Resonance Spectroscopy: an introduction to principles, applications, and experimental methods. Pearson/Prentice Hall, ISBN 0130890669 9780130890665, Upper Saddle River, USA.

Laverde Jr., A., Conceição, G.J.A., Queiroz, S.C.N., Fujiwara, F.Y. \& Marsaioli, A.J. (2002). An NMR tool for cyclodextrin selection in enantiomeric resolution by highperformance liquid chromatography. Magnetic Resonance in Chemistry, Vol. 40, Issue 7, (May 2002), pp. 433-442, DOI 10.1002/mrc.1043

Li, S. \& Purdy, W.C. (1992). Cyclodextrins and their applications in analytical chemistry. Chemical Review, Vol. 92, No 6, (September 1992), pp. 1457-1470, DOI 10.1021/cr00014a009

Lima, S., Gonçalves, I.S., Ribeiro-Claro, P., Pillinger, M., Lopes A.D., Ferreira, P., TeixeiraDias, J.J.C., Rocha, J. \& Romão C.C. (2001). Interactions of cationic and neutral molybdenum complexes with $\beta$-cyclodextrin host molecules. Organometallics, Vol. 20, N 11, (May 2001), pp. 2191-2197, DOI 10.1021/om001088s

Lin, M., Jayawickrama, D.A., Rose, R.A., DelViscio, J.A. \& Larive, C.K. (1995). NMR spectroscopic analysis of the selective complexation of the cis and trans isomers of phenylalanyl-proline by $\beta$-cyclodextrin. Analytica Chimica Acta, Vol. 307, Issues 2-3, (May 1995), pp. 449-457, DOI 10.1016/0003-2670(95)00006-L

Loukas, Y.L. (1997). Multiple complex formation of fluorescent compounds with cyclodextrins: efficient determination and evaluation of the binding constant with 
improved fluorometric studies. The Journal of Physical Chemistry B, Vol. 101, Issue 24, (June 1997), pp. 4863-4866, DOI 10.1021/jp9638189

Mathur, R., Becker, E.D., Bradley, R.B. \& Li, N.C. (1963). Proton magnetic resonance studies of hydrogen bonding of benzenethiol with several hydrogen acceptors. Journal of Physical Chemistry, Vol. 67, Issue 10, (October 1963), pp. 2190-2194, DOI 10.1021/j100804a052

Morris, K.F. \& Johnson Jr., C.S. (1992). Diffusion-ordered two-dimensional nuclear magnetic resonance spectroscopy. Journal of the American Chemical Society, Vol. 114, $\mathrm{N}^{\circ} 8$, (April 1992), pp. 3139-3141, DOI 10.1021/ja00034a071

Neuhaus, D. \& Williamson, M. (2000). The nuclear Overhauser effect in structural and conformation analysis. Wiley-VHC, Inc., ISBN 0-471-24675-1, New York, USA.

Parella, T. (1998). Pulsed field gradients: a new tool for routine NMR. Magnetic Resonance in Chemistry, Vol. 36, Issue 7, (July 1998), pp. 467-495, DOI 10.1002/(SICI)1097458X(199807)36:7<467::AID-OMR325>3.0.CO,2-S

Pinto, L.M.A., Fraceto, L.F., Santana, M.H.A., Pertinhez T.A., Oyama Jr.,' S. \& de Paula, E. (2005). Physico-chemical characterization of benzocaine- $\beta$-cyclodextrin inclusion complexes. Journal of Pharmaceutical and Biomedical Analysis, Vol. 39, Issue 5, (October 2005), pp. 956-963, DOI 10.1016/j.jpba.2005.06.010

Price, W.S. (1997). Pulsed-field gradient nuclear magnetic resonance as a tool for studying translational diffusion: Part 1. Basic theory. Concepts in Magnetic Resonance, Vol. 9, Issue 5, (December, 1997), pp. 299-336, DOI 10.1002/ (SICI)10990534(1997)9:5<299::AID-CMR2>3.0.CO,2-U

Rasheed, A., Kumar C.K.A., Sravanthi V.V.N.S.S. (2008). Cyclodextrins as drug carrier molecule: A review. Scienthia Pharmaceutica, Vol. 76, (November 2008), pp. 567-598, DOI 10.3797/scipharm.0808-05

Rymdén, R., Carlfors, J. \& Stilbs, P. (1983). Substrate binding to cyclodextrins in aqueous solution: A multicomponent self-diffusion study. Journal of Inclusion Phenomena and Macrocyclic Chemistry, Vol. 1, N² (June 1983), pp. 159-167, DOI 10.1007/BF00656818

Saenger, W. (1980). Cyclodextrin inclusion compounds in research and industry. Angewandte Chemie International Edition in English, Vol.19, Issue 5, (April 1980), pp. 344-362, DOI 10.1002/anie.198003441

Saito, H., Ando, I. \& Naito, A. (2006). Solid state NMR spectroscopy for biopolymers: principles and applications. Springer, ISBN: 10 1-4020-4302-3, Dordrecht, The Netherlands.

Santos, J.-F.R., Alvarez-Lorenzo, C., Silva, M., Balsa, L., Couceiro, J., Labandeira J.J.T., Concheiro, A. (2009). Soft contact lenses functionalized with pendant cyclodextrins for controlled drug delivery. Biomaterials, Vol. 30, Issue 7, (March 2009), pp. 13481355, DOI 10.1016/j.biomaterials.2008.11.016

Schneider, H.-J, Hacket, F, Rüdiger, V. \& Ikeda, H. (1998). NMR studies of cyclodextrins and cyclodextrin complexes. Chemical Reviews, Vol. 98, Issue 5, (July 1998), pp. 17551785, DOI 10.1021/cr970019t

Servais, A.-C., Rousseau, A., Fillet, M., Lomsadze, K., Salgado, A., Crommen, J. \& Chankvetadze, B. (2010). Capillary electrophoretic and nuclear magnetic resonance studies on the opposite affinity pattern of propranolol enantiomers towards various cyclodextrins. Journal of Separation Science, Vol. 33, Issue 11, (June 2010), pp. 1617-1624, DOI 10.1002/jssc.201000040

Simova, S. \& Berger, S. (2005). Diffusion measurements vs. chemical shift titration for determination of association constants on the example of camphor-cyclodextrin complexes. Journal of Inclusion Phenomena and Macrocyclic Chemistry, Vol. 53, No 3 , (February 2005), pp. 163-170, DOI 10.1007/s10847-005-2631-5 
Sohajda, T., Varga, E., Iványi, R., Fejõs, I., Szente, L., Noszál, B. \& Béni, S. (2010). Separation of vinca alkaloid enantiomers by capillary electrophoresis applying cyclodextrin derivatives and characterization of cyclodextrin complexes by nuclear magnetic resonance spectroscopy. Journal of Pharmaceutical and Biomedical Analysis, Vol. 53, Issue 5, (December 2010), pp. 1258-1266, DOI 10.1016/j.jpba.2010.07.032

Souza, A.A. \& Laverde Jr., A. (2002). Aplicação da espectroscopia de ressonância magnética nuclear para estudos de difusão molecular em líquidos: a técnica DOSY. Quimica Nova, Vol. 25, N 6, (February 2002), pp. 10220-1026, ISSN 1678-7064

Steed, J.W. \& Atwood, J.L. (2002). Supramolecular Chemistry. John Wiley \& Sons Ltd, ISBN 978-0-470-51234-0 (Pbk), Chichester, England.

Stilbs, P. (1987). Fourier transform pulsed-gradient spin-echo studies of molecular diffusion. Progress in Nuclear Magnetic Resonance Spectroscopy, Vol. 19, Issue 1, (1987), pp. 1-45, DOI 10.1016/0079-6565(87)80007-9

Szejtli, J. (1988). Cyclodextrin Technology. Kluwer Academic Publishers, ISBN 979-90-48184279, Dordrecht, The Netherlands.

Szejtli, J. (1998). Introduction and general overview of cyclodextrin chemistry. Chemical Reviews, Vol. 98, (January 1998), pp. 1743-1753, DOI S0009-2665(97)00022-8

Tamamoto, L.C., Schmidt, S.J. \& Lee, S.-Y. (2010). Sensory properties of ginseng solutions modified by masking agents. Journal of Food Science, Vol. 75, Issue 7, (September 2010), pp. S341-S347, DOI 10.1111/j.1750-3841.2010.01749.x

Tang, B., Wang, X., Liang, H., Jia, B. \& Chen, Z. (2005). Study on the supramolecular interaction of thiabendazole and $\beta$-cyclodextrin by apectrophotometry and its analytical application. Journal of Agricultural and Food Chemistry, Vol. 22, $\mathrm{N}^{\circ} 53$, (October 2005), pp. 8452-8459, DOI 10.1021/jf051683a

Tanner, J.E. (1970). Use of the stimulated echo in NMR diffusion studies. Journal of Chemical Physics, Vol. 52, No 5, (March 1970), pp. 2523-2525, DOI 10.1063/1.1673336

Thakkar, A.L. \& Demarco, P.V. (1971). Cycloheptaamylose inclusion complexes of barbiturates: correlation between proton magnetic resonance and solubility studies. Journal of Pharmaceutical Science, Vol. 60, Issue 4, (April 1971), pp. 652-653, DOI $10.1002 /$ jps.2600600444

Uekama, K., Hirayama, F. \& Irie, T. (1998). Cyclodextrin drug carrier systems. Chemical Reviews, Vol. 98, Issue 5, (June 1998), pp. 2045-2076, DOI 10.1021/cr970025p

Voulgari, A., Benaki, D., Michaleas, S. \& Antoniadou-Vyza, E. (2007). The effect of $\beta$ cyclodextrin on tenoxicam photostability, studied by a new liquid chromatography method, the dependence on drug dimerisation. Journal of Inclusion Phenomena and Macrocyclic Chemistry, Vol. 57, Issues 1-4, (April 2007), pp. 141-146, DOI 10.1007/s10847-006-9206-y

Woessner, D.E. (1961). Effects of diffusion in Nuclear Magnetic Resonance spin-echo experiments. Journal of Chemical Physics, Vol. 34, N 6, (June 1961), pp. 2057-2061, DOI 10.1063/1.1731821

Wozel, G., Blasum, C., Winter, C. \& Gerlach, B. (1997). Dapsone hydroxylamine inhibits the LTB4-induced chemotaxis of polymorphonuclear leukocytes into human skin: results of a pilot study. Inflammatory Research, Vol. 46, N 10, (October 1997), pp. 420-422, DOI 10.1007/s000110050215

Yorozu, T., Hoshino, M., Imamura, M. \& Shizuka, H. (1982). Photoexcited inclusion complexes of .beta.-naphthol with alpha-, beta-, and gamma-cyclodextrins in aqueous solutions. Journal of Physical Chemistry, Vol. 86, N²2, (October 1982), pp. 4422-4426, DOI 10.1021/j100219a030 


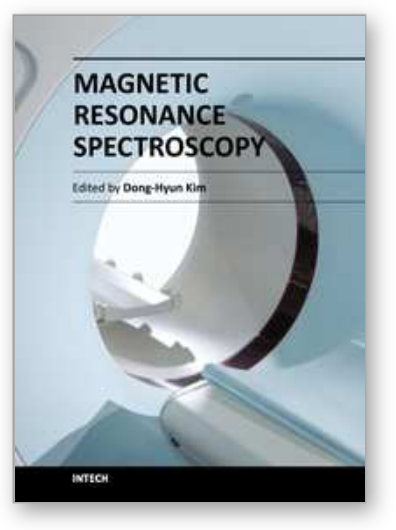

\author{
Magnetic Resonance Spectroscopy \\ Edited by Prof. Dong-Hyun Kim
}

ISBN 978-953-51-0065-2

Hard cover, 264 pages

Publisher InTech

Published online 02, March, 2012

Published in print edition March, 2012

Magnetic Resonance Spectroscopy (MRS) is a unique tool to probe the biochemistry in vivo providing metabolic information non-invasively. Applications using MRS has been found over a broad spectrum in investigating the underlying structures of compounds as well as in determining disease states. In this book, topics of MRS both relevant to the clinic and also those that are beyond the clinical arena are covered. The book consists of two sections. The first section is entitled 'MRS inside the clinic' and is focused on clinical applications of MRS while the second section is entitled 'MRS beyond the clinic' and discusses applications of MRS in other academic fields. Our hope is that through this book, readers can understand the broad applications that NMR and MRS can offer and also that there are enough references to guide the readers for further study in this important topic.

\title{
How to reference
}

In order to correctly reference this scholarly work, feel free to copy and paste the following:

Francisco B. T. Pessine, Adriana Calderini and Guilherme L. Alexandrino (2012). Review: Cyclodextrin Inclusion Complexes Probed by NMR Techniques, Magnetic Resonance Spectroscopy, Prof. Dong-Hyun Kim (Ed.), ISBN: 978-953-51-0065-2, InTech, Available from: http://www.intechopen.com/books/magneticresonance-spectroscopy/review-study-of-inclusion-complexes-with-cyclodextrins-by-mrs

\section{INTECH}

open science | open minds

\author{
InTech Europe \\ University Campus STeP Ri \\ Slavka Krautzeka 83/A \\ 51000 Rijeka, Croatia \\ Phone: +385 (51) 770447 \\ Fax: +385 (51) 686166 \\ www.intechopen.com
}

\author{
InTech China \\ Unit 405, Office Block, Hotel Equatorial Shanghai \\ No.65, Yan An Road (West), Shanghai, 200040, China \\ 中国上海市延安西路65号上海国际贵都大饭店办公楼405单元 \\ Phone: +86-21-62489820 \\ Fax: +86-21-62489821
}


(C) 2012 The Author(s). Licensee IntechOpen. This is an open access article distributed under the terms of the Creative Commons Attribution 3.0 License, which permits unrestricted use, distribution, and reproduction in any medium, provided the original work is properly cited. 